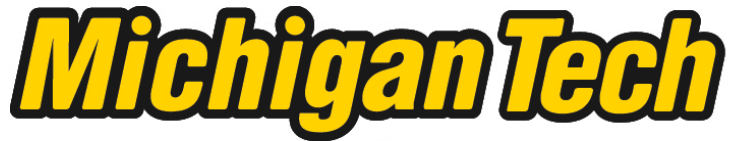 \\ Michigan Technological University Create the Future Digital Commons @ Michigan Tech
}

Dissertations, Master's Theses and Master's Reports - Open

Dissertations, Master's Theses and Master's

Reports

2014

FACTORS INFLUENCING MATERIAL LOSS DURING IRON ORE PELLET HANDLING

Joseph A. Halt

Michigan Technological University

Follow this and additional works at: https://digitalcommons.mtu.edu/etds

Part of the Chemical Engineering Commons

Copyright 2014 Joseph A. Halt

\section{Recommended Citation}

Halt, Joseph A., "FACTORS INFLUENCING MATERIAL LOSS DURING IRON ORE PELLET HANDLING", Master's Thesis, Michigan Technological University, 2014.

https://doi.org/10.37099/mtu.dc.etds/748

Follow this and additional works at: https://digitalcommons.mtu.edu/etds

Part of the Chemical Engineering Commons 


\title{
FACTORS INFLUENCING MATERIAL LOSS DURING IRON ORE PELLET
} HANDLING

By

Joseph A. Halt

\begin{abstract}
A THESIS
Submitted in partial fulfillment of the requirements for the degree of MASTER OF SCIENCE

In Chemical Engineering
\end{abstract}

MICHIGAN TECHNOLOGICAL UNIVERSITY

2014

(C) 2014 Joseph A. Halt 
This thesis has been approved in partial fulfillment of the requirements for the Degree of MASTER OF SCIENCE in Chemical Engineering

Department of Chemical Engineering

Thesis Advisor: Dr. S. Komar Kawatra

Committee Member: Dr. Julia A. King

Committee Member: $\quad$ Dr. Bruce J. Pletka

Department Chair: Dr. S. Komar Kawatra 


\section{Table of Contents}

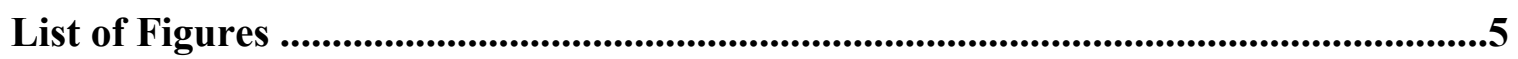

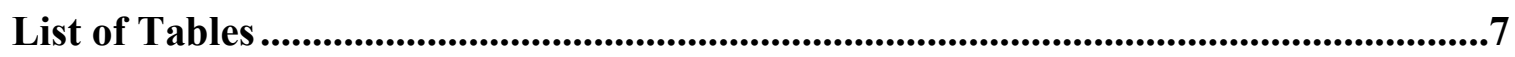

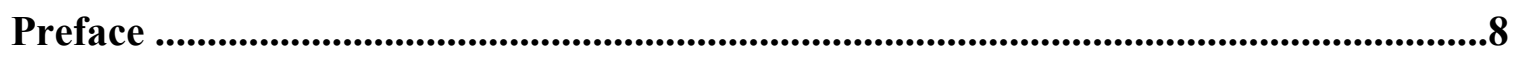

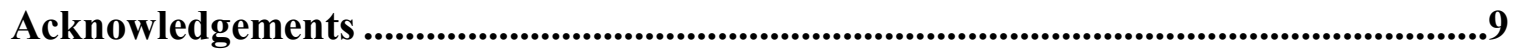

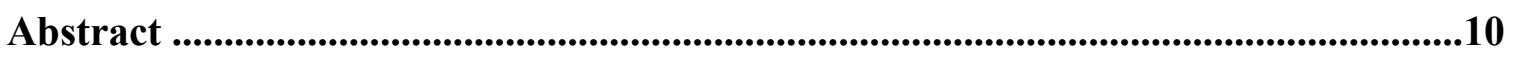

1 General Introduction and Objectives ............................................................11

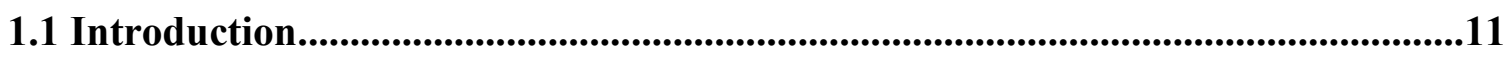

1.2 Research Objectives........................................................................................11

2 Factors affecting dust generation from iron ore concentrate pellets ......................12

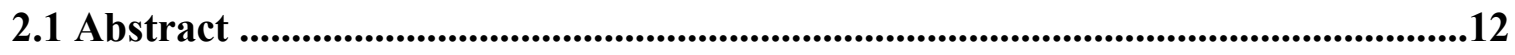

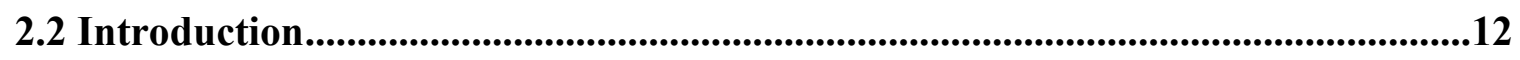

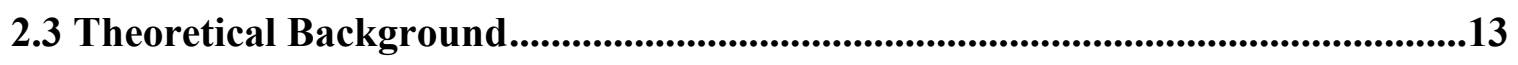

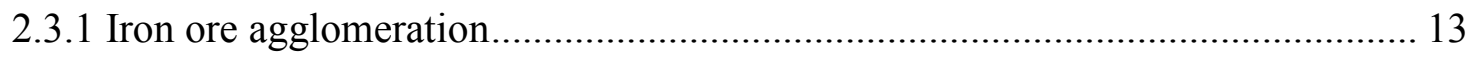

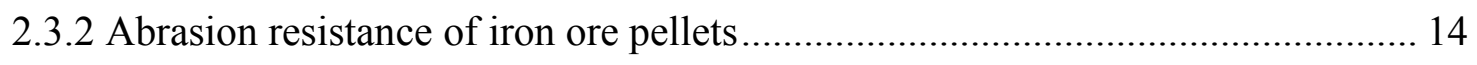

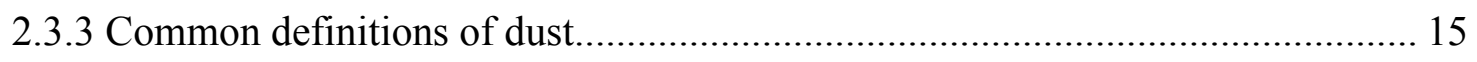

2.4 Materials and Experimental Methods .......................................................................16

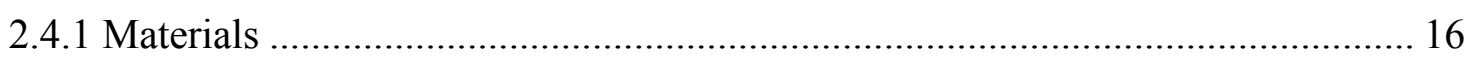

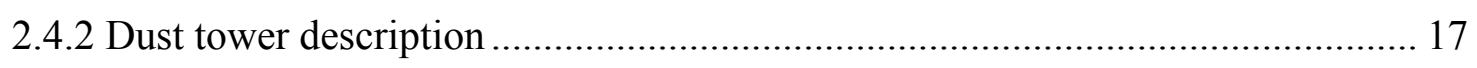

2.4.3 Effects of experimental parameters on cumulative mass measurements............ 19

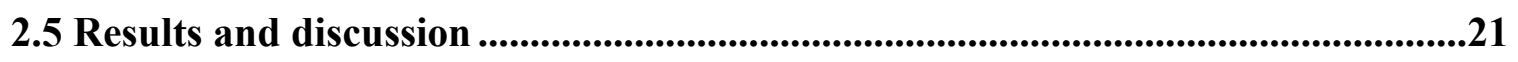

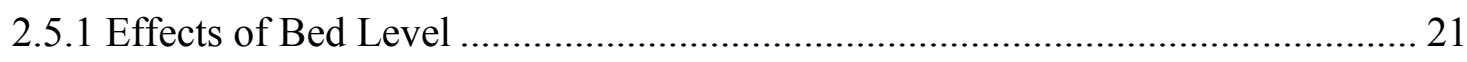

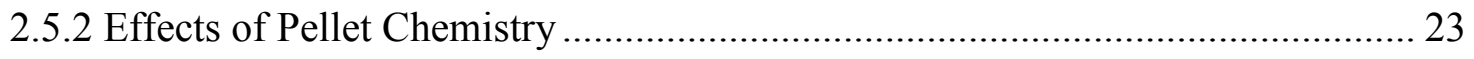

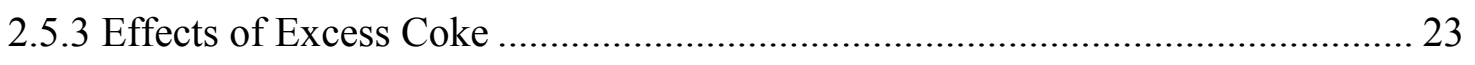

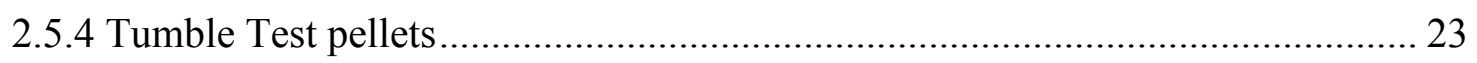

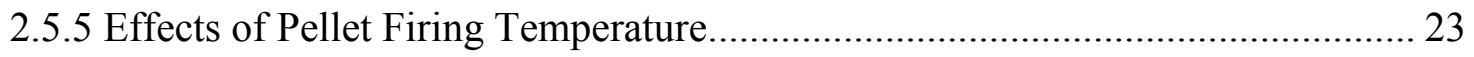

2.5.6 Comparison between Cumulative Airborne Mass and Abrasion Index.............. 24

2.6 Conclusions ..............................................................................................................................27 
3 Effects of firing route and abrasion resistance on fines and dust generation .........29

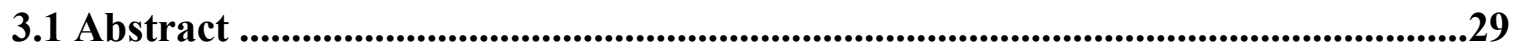

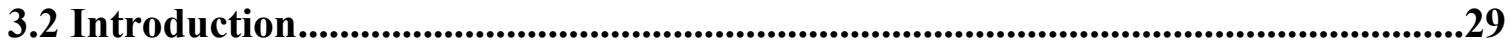

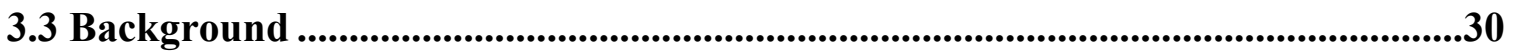

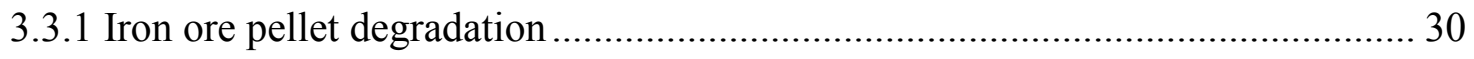

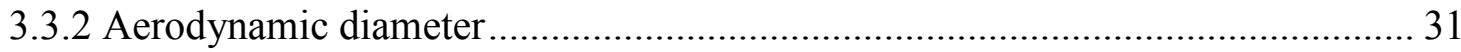

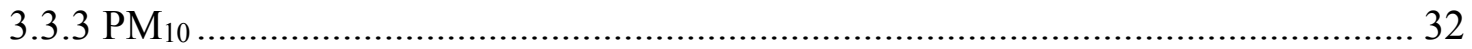

3.4 Materials and Experimental Methods ..................................................................32

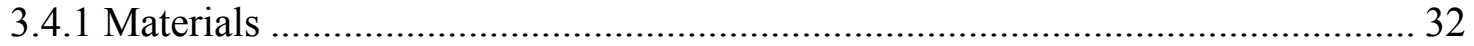

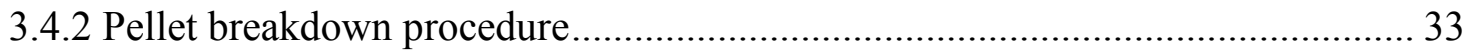

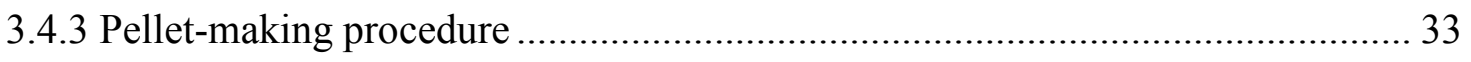

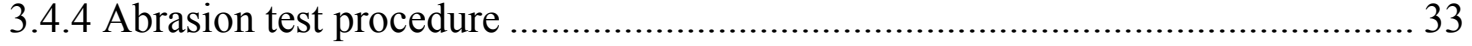

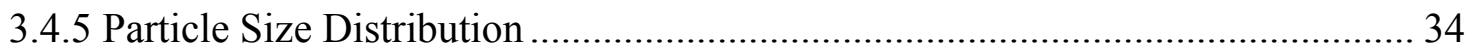

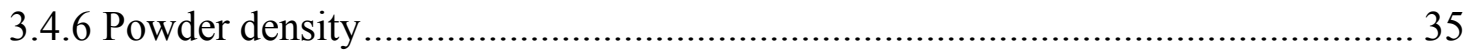

3.4.7 Calculating the quantity of $\mathrm{PM}_{10}$ generated during abrasion ........................... 35

3.5 Results and Discussion .........................................................................................35

3.5.1 Breakdown of iron ore concentrate pellets ................................................ 35

3.5.2 Abrasion resistance of iron ore concentrate pellets ...................................... 38

3.5.3 Regression between pellet dustiness and the Abrasion Index .......................... 42

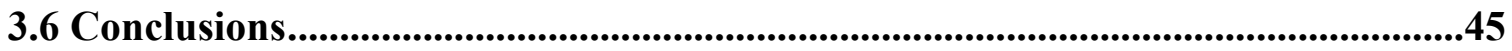

4 References..................................................................................................................................46 


\section{List of Figures}

Figure 1 Potential factors controlling the dustiness of iron ore concentrate pellets 14

Figure 2 Calculated aerodynamic diameter, in $\mu \mathrm{m}$, as a function of particle density, in $\mathrm{kg} / \mathrm{m}^{3}$, and diameter, in $\mu \mathrm{m}$. For these calculations, particles were assumed to be spherical with a shape factor of 1 . 16

Figure 3 MTU dust tower schematic (1) and laboratory experimental set-up (r)............ 19

Figure 4 Cumulative airborne mass collected after each drop through the dust tower.... 20

Figure 5 Cumulative airborne mass for each pellet type tested. Pellet samples are a) bed level; b) pellet chemistry; c) excess coke 1; d) excess coke 2; e) tumble testing; and f) firing temperature. Cumulative airborne mass reported after 5 drops through tower. "TI" indicates Tumble Index. "HME" indicates heat of magnetite equivalent, and represents the quantity of coke breeze added to green-balls. "Adj. fire" indicates an adjustment to the pot-grate firing procedure.

Figure 6 Correlation between total cumulative dust $(\mathrm{mg} / \mathrm{kg})$ and Abrasion Index $(\%<0.5$ $\mathrm{mm}$ ). Two data points beyond $10 \% \mathrm{AI}$ (firing temperature 1050 and $1200{ }^{\circ} \mathrm{C}$ ) have been excluded for clarity. 25

Figure 7 SEM micrographs of airborne particles collected while handling various types of pellets: a) Pellet Chemistry-Condition E, scale bar $300 \mu \mathrm{m}$; b) Pellet ChemistryCondition F, scale bar $20 \mu \mathrm{m}$; c) Pellet Chemistry-Condition C, scale bar $20 \mu \mathrm{m}$. 26

Figure 8 Pellet degradation by impact (left) and abrasion (right), and their resulting particle size distributions. Fragmentation produces a wide distribution. Abrasion produces a bimodal distribution that consists of the original coarse particles and very fine powder. 30

Figure 9 Procedure for calculating the quantity of $\mathrm{PM}_{10}$ produced during abrasion. $\mathrm{PM}_{10}$ percentiles from each sample were multiplied by the percentage of $-0.5 \mathrm{~mm}$ fines produced at that time interval. This example data shown is from type $\mathrm{C}$ pellets. 34

Figure 10 Fines generation rate for industrial pellets fired in SG and GK furnaces. Fines were generated by agitating one kilogram of +3 mesh pellets using a Tyler Rotap for 15 
minutes. Fines were defined as the quantity of -35 mesh material produced during the test. The errors bars represent the standard deviations of 4 measurements for each sample.

Figure 11 Generation rate of minus 10 micrometers particles as a function of fines generation rates. One kilogram of +3 mesh pellets were agitated using a Tyler Rotap for 15 minutes. Fines were defined as the quantity of -35 mesh material produced during the test. Particle size distributions were found using a Microtrac particle size analyzer. ...... 37

Figure 12 Effects of binders and firing temperature on the abrasion index of laboratory pellets. Unless otherwise indicated, all pellets were fired at $1250^{\circ} \mathrm{C}$. Closed symbols are laboratory pellets made from concentrate $\mathrm{D}$. Open symbols are laboratory pellets made from concentrate $\mathrm{F}$. LMW = low molecular weight. $\mathrm{HMW}=$ high molecular weight. $\mathrm{MW}$ $=$ molecular weight. The firing temperature samples were made using $6.6 \mathrm{~kg} / \mathrm{t}$ bentonite clay as the binder.

Figure 13 Effect of revolution time on abrasion powder fineness. Laboratory pellets made from Plant D concentrate. Organic binders at $1.0 \mathrm{~kg} / \mathrm{t}$. Firing temperature $1250{ }^{\circ} \mathrm{C}$.

Figure 14 Effects of abrasion index on abrasion product fineness. As pellet quality improves (AI decreases), the degradation products generally become finer. The Abrasion Index was defined as the quantity of $-0.5 \mathrm{~mm}$ fines produced after 30 minutes, normalized to the initial pellet charge.

Figure 15 Effects of Abrasion Index on the total quantity of dust generated by abrasion. Only pellets with $\mathrm{AI}<5 \%$ are shown. The Abrasion Index was defined as the quantity of $-0.5 \mathrm{~mm}$ fines produced after 30 minutes, normalized to the initial pellet charge. Dust was defined as the quantity of $\mathrm{PM}_{10}$ particles, normalized to the initial pellet charge.

Figure 16 Cross-sectional micrographs of iron ore pellets at various AI and total $\mathrm{PM}_{10}$. Micrographs were taken near the pellet surface. Microstructure and bonding of grains are shown at left (scale bar $50 \mu \mathrm{m}$ ), while overall pellet structure and porosity are shown at right (scale bar $500 \mu \mathrm{m}$ ). 


\section{List of Tables}

Table 1 Iron ore pellet sample description. Industrial pellet samples were supplied by industrial pellet plants. Laboratory pellet samples were made at COREM. "TI" indicates Tumble Index. "HME" indicates heat of magnetite equivalent, and represents the quantity of coke breeze added to green-balls. "Adj. fire" indicates an adjustment to the pot-grate firing procedure. A mini-tumble test was conducted on some samples when too few pellets were available for the ISO procedure.

Table 2 Industrial pellet characterization. Table notes: S.G. = Specific Gravity; Screen size distribution determined by sieve analysis. Pellet S.G. determined following ASTM C914-09 


\section{Preface}

The work contained in this thesis has been submitted as a two-part series on the dustiness of iron ore pellets:

1. Halt, J.A., Nitz, M.C., Kawatra, S.K., and Dubé, M., (2013) "Iron ore pellet dustiness Part I: Factors affecting dust generation”, Under Review.

2. Halt, J.A., Kawatra, S.K., (2013) "Iron ore pellet dustiness Part I: Effects of firing route and abrasion resistance on fines and dust generation", Under Review.

A description of the coauthors' contributions is as follows:

S.K. Kawatra, Professor and Chair, Department of Chemical Engineering, Michigan Technological University, contributed as my advisor during this work.

M.C. Nitz, undergraduate student, Department of Chemical Engineering, Michigan Technological University, helped to characterize the operation and performance of the dust tower, and performed some dustiness measurements reported in Paper 1.

M. Dubé, Researcher and Program Leader-Pelletizing and Thermal Processes, COREM, contributed as a consultant and supplied the majority of the pellet types reported in Paper 1. 


\section{Acknowledgements}

I would like to sincerely thank S. Komar Kawatra for the invaluable opportunity to learn about mineral processing. Sincere thanks are also extended to those ASISC members and contributors who have kindly supported the ASISC center and its research. Mark Preston, Aaron Steeg and David Hutchison, students in the Department of Chemical Engineering at Michigan Technological University, participated in some of these experiments during their undergraduate curriculums and deserve recognition - their work was greatly appreciated.

Thank you to Dr. Julie King and Dr. Bruce Pletka for sacrificing their time and serving on my committee, and to the anonymous reviewers who have reviewed this work in manuscript form. All of their efforts are appreciated. 


\section{Abstract}

Iron ore concentrate pellets have the potential to fracture and abrade during transportation and handling, which produces unwanted fine particulates and dust. Consequently, pellet producers characterize the abrasion resistance of their pellets, using an Abrasion Index (AI), to indicate whether their products will produce unacceptable levels of fines. However, no one has ever investigated whether the AI correlates to pellet dustiness.

During the course of this research, we investigated the relationship between AI and iron ore concentrate pellet dustiness using a wide range of industrial and laboratory pellet samples. The results showed that, in general, AI can be used to indicate high levels of dust. However, for good-quality pellets, there was no correlation between the two. Thus, dust generation from shipping and handling pellets will depend on the quantity of pellets handled and how much they are handled. These results also showed that the type of industrial furnace used to harden iron ore concentrate pellets may affect their fines generation and potential dustiness. 


\section{General Introduction and Objectives}

\subsection{Introduction}

Bulk granular products such as limestone, coal, fertilizer and iron ore degrade during their production and handling, generating small particles called "fines". Structurally weak granules tend to produce significant quantities of fines by both impact and abrasion, while competent materials (e.g. iron ore concentrate pellets) tend to produce fines solely by abrasion. In either case, the generation of fines is unwanted and can lead to material losses and emissions of fugitive dust.

In the iron ore concentrate pelletizing industry, the Abrasion Index (AI) is used to indicate the abrasion resistances of pellets. The Abrasion Index (AI) is defined as the quantity of "fines" (material finer than $0.5 \mathrm{~mm}$ by ISO 3271:2007 or $0.6 \mathrm{~mm}$ by ASTM E279-97) produced while pellets tumble in a rotating drum. Historically, the AI has been one of the best indicators of pellet quality, and a low value is desired. However, its potential relationship to pellet dustiness has never been investigated!

Specifically in this research we asked: "Does the Abrasion Index correlate to a $\mathrm{PM}_{10}$ Index?" $\mathrm{PM}_{10}$, or the quantity of particulate matter with aerodynamic diameter $10 \mu \mathrm{m}$ and smaller, is a very specific and relevant definition of dust. Particles included as fines in the AI test may be considered quite coarse relative to $\mathrm{PM}_{10}$.

\subsection{Research Objectives}

This research was conducted with two objectives in mind:

1. Design a simple, robust test that can be used to measure the generation of $\mathrm{PM}_{10}$ from iron ore pellets.

2. Evaluate the effects of major pelletizing variables on the Abrasion Index and $\mathrm{PM}_{10}$ Index of iron ore concentrate pellets.

Consequently, this thesis is logically structured following these objectives. Chapter 2 presents the dustiness of many types of industrial and laboratory pellets obtained using a "dust tower", and shows a poor correlation between AI and dustiness. Chapter 3, describes effects of industrial pelletizing furnaces on fines generation in a rotating drum, and provides one explanation why AI may not correlate to dustiness. 


\section{Factors affecting dust generation from iron ore concentrate pellets ${ }^{1}$}

\subsection{Abstract}

Iron ore pellets abrade during handling and produce dust. The research reported in Chapter 2 was conducted to determine what factors affect pellet dustiness, and whether dustiness can be related to the abrasion index. Factors studied included bed depth within a straight grate furnace; pellet chemistry; firing temperature; coke breeze addition; and tumble index. Abrasion indices for all pellet samples ranged from 1.9-5.0 \% (20 samples) and from 7.1$27.5 \%$ (5 samples). Pellets were dropped in an enclosed tower, which enabled the collection of airborne particles generated during pellet breakdown. The quantity of airborne particles generated by each pellet type was $10-100 \mathrm{mg} / \mathrm{kg}$-drop, or $50-500 \mathrm{mg} / \mathrm{kg}$ over five drops through the tower. Pellet dustiness was predominantly affected by pellet chemistry and by pellet firing temperature. Results showed a nearly 21 percent increase in dustiness for every percent decrease in firing temperature - this was based on a typical firing temperature of $1280{ }^{\circ} \mathrm{C}$. Pellet dustiness was regressed to the pellet abrasion index (for AI $<5 \%$ ), which yielded a correlation coefficient of 0.22 . These results show that, although $\mathrm{AI}$ is one of the best indicators of fired pellet quality and can indicate high levels of dust, it could not explain the dustiness of good quality pellets.

Chapter 3 explains the relationship between AI and dust for good-quality pellets; and compares fines generation between pellets fired in Straight-Grate (Traveling Grate) and Grate-Kiln furnaces.

\subsection{Introduction}

The mineral processing industry is trending towards the zero-waste approach, which includes minimizing particulate matter emissions. One concern includes the shipping and handling of high-tonnage products, ranging from coal and iron ore to limestone and fertilizer granules. These types of bulk granular materials can fracture and abrade during handling and load-out, generating particulate fragments across a wide range of sizes. Certain particle sizes are able to become airborne and are undesired for many reasons. Commonly cited are health and industrial problems associated with various size ranges of emitted particles and their concentrations.

\footnotetext{
${ }^{1}$ Halt, J.A., Nitz, M.C., Kawatra, S.K., and Dubé, M., (2013) "Iron ore pellet dustiness Part I: Factors affecting dust generation" Under Review
} 
Dust and particulate matter emissions are commonly combated by spraying copious amounts of water and/or applying various types of chemical reagents to storage piles and material transfer points. These chemicals bind particles together, increase particle wetting and water retention and can effectively reduce dust (Copeland and Kawatra, 2005); although, they must be repeatedly added and do little to limit the generation of fine particles.

Alternatively, one could ask whether the generation of finely-sized particles can be reduced. In other words, what controls the generation of potential dust particles when handling bulk granules? Do changes in processing conditions alter quantities of dust generated during handling? Do certain processing conditions lead to higher levels of dustiness? Can the knowledge of dust generation be used to better predict appropriate levels of chemical reagents required for dust suppression and when dust suppression will be needed?

The purpose of this paper is to determine whether the abrasion index can be related to pellet dustiness. Direct measurements of airborne mass, generated by handling various types of pellets in a drop tower, are compared to pellet abrasion indices. Iron ore pellets were of considerable regional interest, as approximately 50 million tons of pellets are produced and shipped per year in the Great Lakes region of the upper Midwest, U.S.A.

\subsection{Theoretical Background}

\subsubsection{Iron ore agglomeration}

Iron ore pellets are used to produce iron and steel. Pellets enable iron-rich powder to be used in blast furnaces and direct reduction shaft furnaces. Moist, finely-sized, iron-rich powder (-300 mesh), powdered flux materials (limestone $/ \mathrm{CaCO}_{3}$ and dolomite $\left./(\mathrm{Ca}, \mathrm{Mg}) \mathrm{CO}_{3}\right)$ and binders are rolled into spherical balls, and subsequently heat hardened into pellets. Factors affecting pellet dustiness can range from inputs to agglomeration; to induration or heat hardening conditions; to the type and extent of handling - all may interact to some degree to affect final pellet structure and properties and ultimately dust generation (Figure 1). 
Agglomeration inputs

- Iron ore mineralogy

- Binder type and dose

- Flux type and dose

Induration conditions

- Firing temperature

- Heating/cooling rate

- Furnace type

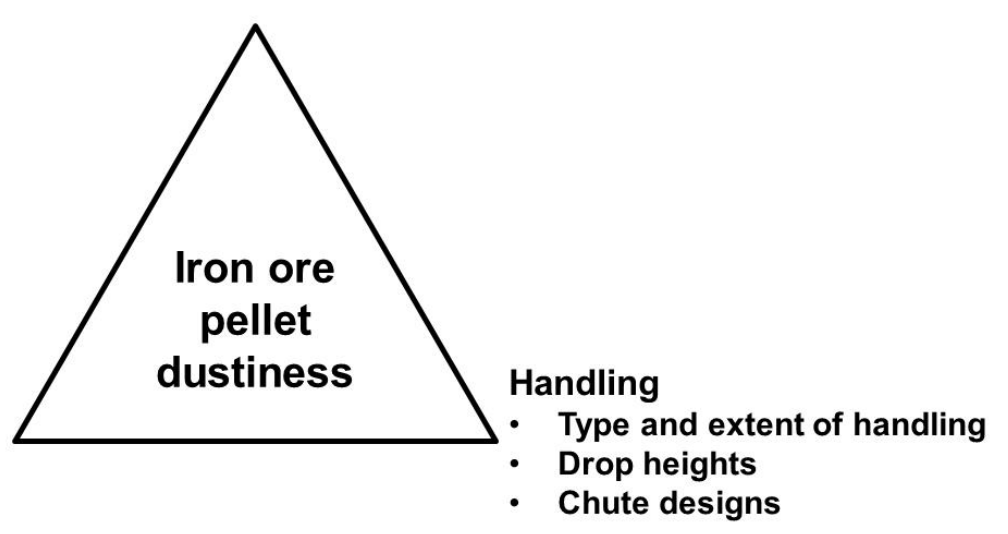

Figure 1 Potential factors controlling the dustiness of iron ore concentrate pellets

\subsubsection{Abrasion resistance of iron ore pellets}

Abrasive wear of granular materials tends to produce fine particles with little change in the original granule size distribution (Pierce et al., 1980). The fine particles from abrasion then contribute to dust while handling pellets. Consequently, we investigated whether a) variables that alter pellet quality and abrasion indices also affect their dustiness; and b) the Abrasion Index can be used as an empirical indicator of pellet dustiness.

Standardized tests are used to report the abrasion resistance of pellets. The Abrasion Index, or AI, reports the percent of material smaller than $600 \mu \mathrm{m}$ (ASTM E279-97) or $500 \mu \mathrm{m}$ (ISO 3271:2007) generated during a tumble test. A higher AI signifies weaker pellets that degrade more easily and produce more fines. Maximum limits on AI vary with pellet consumer, but are generally desired to be less than five percent using the ISO tumble test (Geerdes et al., 2009).

It is well known that additives such as bentonite clay and calcium hydroxide can lower the abrasion index of iron ore pellets; increasing the ore's specific surface area can lower abrasion indices as well (Meyer, 1980). Others have shown that iron ore pellets from different pelletizing plants generated varying quantities of fine particles $(<600 \mu \mathrm{m})$ using a set of mechanically agitated screens (Copeland and Kawatra, 2005). The controlling factor was speculated to be differing types of furnaces used to heat-harden the pellets. It is generally accepted that pellets indurated in Straight-Grate and Rotary Kiln furnaces produce different quantities of before-tumble fines (Oja, 2013). This is due to differences 
in firing uniformity between the two types of furnaces. Additionally, the tumbling action in rotary kilns may remove particles weakly attached to the agglomerate structure.

\subsubsection{Common definitions of dust}

Two relevant particulate size ranges commonly accepted as dust include Total Suspended Particulates and $\mathrm{PM}_{10}$. These particle size ranges are defined using the aerodynamic diameter.

Aerodynamic diameter: The aerodynamic diameter is used to classify particles according to their settling behavior in air (Baron and Willeke, 2001). Imagine dispersing a handful of a dry, non- homogeneous powder into still air and analyzing particles as they settle to the ground. At every instant in time, the particles collected will span ranges of size, density, and shape. All particles that settle at the same rate - and are collected at the same instant in time - can be classified with an equivalent aerodynamic diameter.

The aerodynamic diameter is defined as the size of an idealized spherical particle with a density of $1000 \mathrm{~kg} / \mathrm{m}^{3}$ with equivalent settling behavior as the particle of interest (Baron and Willeke, 2001; EPA, 2013). Simply put, particles with identical aerodynamic behavior can be physically quite different. In general, aerodynamic diameter decreases with particle size, and increases with density and as particles become less spherical. Figure 2 is a plot of calculated aerodynamic diameter $(\mu \mathrm{m})$ as a function of particle density $\left(\mathrm{kg} / \mathrm{m}^{3}\right)$ and diameter $(\mu \mathrm{m})$.

Figure 2 illustrates two general principles. At constant particle density, aerodynamic diameter increases with increasing particle diameter. At constant particle diameter, aerodynamic diameter increases with increasing particle density.

Total suspended particulates: Total suspended particulates, or TSP, includes all dust particles suspended in air that are captured and reported by the sampler. Generally, dust has been considered to be particles with diameters less than 75-100 $\mu \mathrm{m}$ (ISO 4225:1994; IUPAC, 1990). Historical particulate matter regulations set limits on TSP emissions.

$\mathrm{PM}_{10}: \mathrm{PM}_{10}$ consists of particulate matter with an aerodynamic diameter of $10 \mu \mathrm{m}$ or smaller. $\mathrm{PM}_{10}$ may be called coarse, inhalable particles (EPA 2013). 


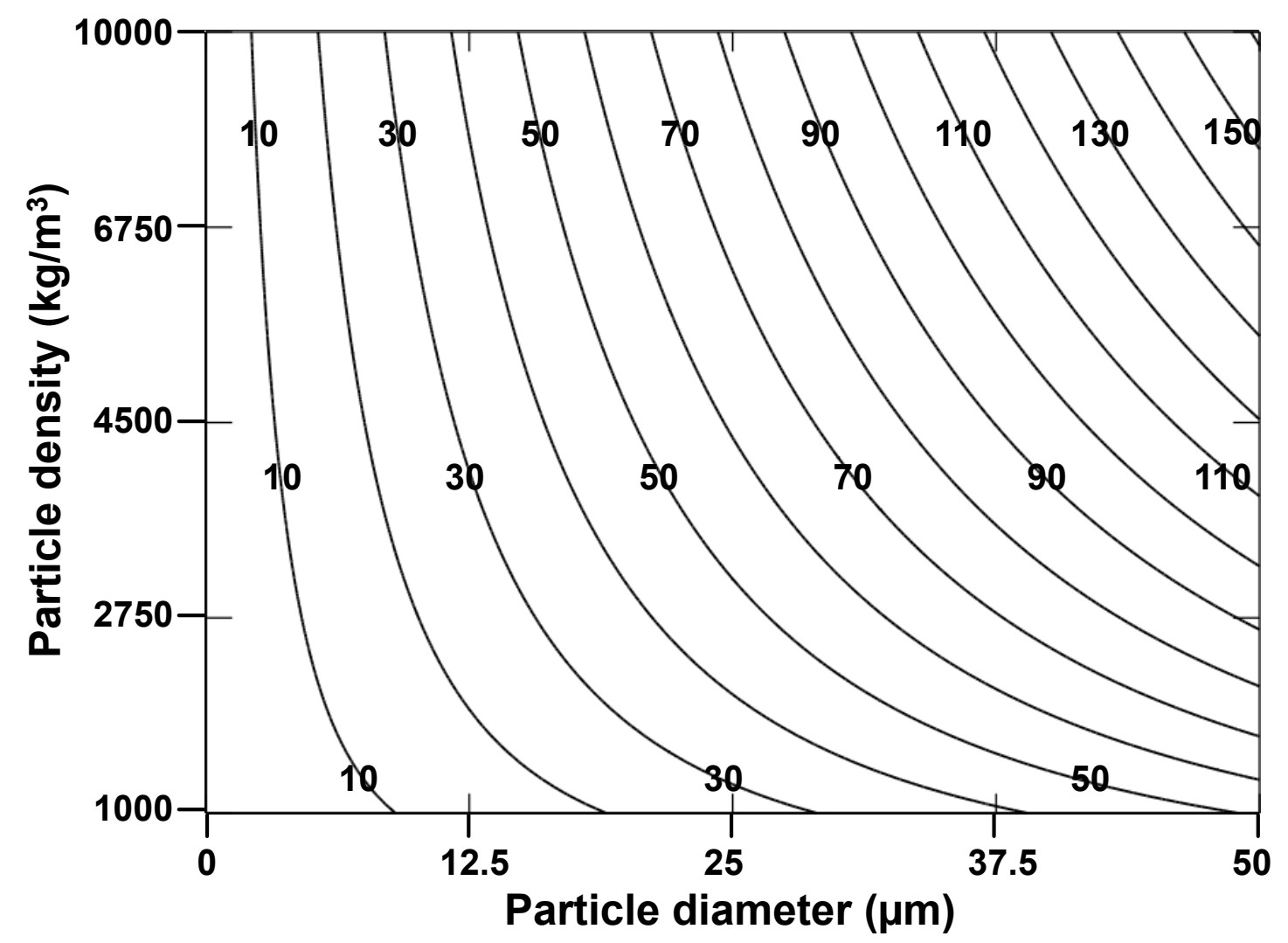

Figure 2 Calculated aerodynamic diameter, in $\mu m$, as a function of particle density, in $\mathrm{kg} / \mathrm{m}^{3}$, and diameter, in $\mu \mathrm{m}$. For these calculations, particles were assumed to be spherical with a shape factor of 1.

\subsection{Materials and Experimental Methods}

\subsubsection{Materials}

Twenty-five types of iron ore pellets were received for dustiness testing. Some samples were made by industrial iron ore pellet plant operations; other samples were made in a laboratory following accepted agglomeration and firing procedures. The pellets were classified into certain groups for comparison, as shown in Table 1. A brief description of each group of pellets is as follows:

Bed level: The "Bed level" pellets were industrial pellet samples. These samples were collected from different depths in a bed of pellets fired in a Straight-Grate furnace.

Pellet chemistry: The "Pellet chemistry" pellets were industrial pellet samples. These samples represent a wide range of chemical and mineralogical contents, as they were 
prepared using a variety of ores, binders and levels of flux. Samples were collected from industrial pelletizing plants, so unavoidable differences in firing conditions may have been present for each sample.

Firing temperature: The "Firing temperature" pellets were laboratory pellet samples. These samples were fired at three temperatures to determine its effects on pellet dustiness.

Excess coke: The "Excess coke" pellets were laboratory pellet samples. These samples were prepared from a hematitic ore and various levels of coke breeze as an internal fuel source. Pellets were made at two basicities. Coke levels are reported as percent HME, or Heat of Magnetite Equivalent. Higher HME is provided by higher levels of coke breeze in the green-balls (un-fired pellets).

Tumble Index: The "Tumble Index" pellets were industrial pellet samples. Two chemistries were provided, each with a "good" and "bad" Tumble Index as indicated by the industrial pellet plant.

\subsubsection{Dust tower description}

The dust tower used in this study was originally designed to test the effectiveness of dust suppressants for iron ore pellets (Copeland and Kawatra, 2011). The height $(2.7 \mathrm{~m})$ was chosen to be representative of typical drop heights at iron ore handling facilities in the Great Lakes region of the upper Midwest, U.S.A. Material dropped through the tower collides with several impact plates; kinetic energy from the fall is dissipated by elastic material deformation, friction during rolling and sliding, and by particle breakage. As the forces seen by each particle are held constant (assuming constant particle mass), the type and extent of particle breakage depends on the material properties and processing history of the handled material. A schematic of the dust tower is shown in Figure 3.

As material falls through the tower, a vacuum system pulls air up through the tower at approximately $8 \mathrm{l} / \mathrm{s}$, entrains certain sized particles produced within the tower, and carries them to a filter paper (Whatman 113, $30 \mu \mathrm{m}$ pore diameter) in the vacuum system line where they are collected for analysis. Based on channel dimensions in the dust tower, a volumetric flow rate of $81 / \mathrm{s}$ corresponds to a $0.6 \mathrm{~m} / \mathrm{s}$ vertical air velocity. $\mathrm{PM}_{10}$ mass concentrations can be measured by an aerosol monitor (TSI DustTrak, model 8520) that samples dust-laden air prior to the particulate filter. 
Table 1 Iron ore pellet sample description. Industrial pellet samples were supplied by industrial pellet plants. Laboratory pellet samples were made at COREM. "TI" indicates Tumble Index. "HME" indicates heat of magnetite equivalent, and represents the quantity of coke breeze added to green-balls. "Adj. fire" indicates an adjustment to the pot-grate firing procedure. A mini-tumble test was conducted on some samples when too few pellets were available for the ISO procedure.

\begin{tabular}{|c|c|c|c|c|c|c|c|}
\hline $\begin{array}{c}\text { Pellet } \\
\text { Variable } \\
\text { Evaluated }\end{array}$ & $\begin{array}{c}\text { Sample } \\
\text { Name }\end{array}$ & Notes & $\begin{array}{c}\text { Fired } \\
\text { Compress } \\
\text { (kgf) } \\
\end{array}$ & \multicolumn{4}{|c|}{ nTumble ISO (\%)Mini-tumble (\%) } \\
\hline \multirow[t]{4}{*}{ Bed level } & Top & Industrial & 327 & & & 96.5 & 3.1 \\
\hline & Middle & pellet & 353 & & & 97.1 & 2.9 \\
\hline & Bottom & samples & 302 & & & 96.8 & 3.1 \\
\hline & Hearth & & 294 & & & 96.3 & 3.7 \\
\hline \multirow{8}{*}{$\begin{array}{c}\text { Pellet } \\
\text { chemistry }\end{array}$} & Plant A & Industrial & 178 & & & 90.9 & 7.2 \\
\hline & Plant C & pellet & 322 & & & 97.0 & 2.4 \\
\hline & Plant E & samples & 204 & & & 97.5 & 1.9 \\
\hline & Plant F & & 215 & & & 95.1 & 4.4 \\
\hline & Plant G & & 239 & & & 94.7 & 4.6 \\
\hline & Plant V & & 276 & & & 95.3 & 4.7 \\
\hline & Plant W & & 276 & & & 95 & 5.0 \\
\hline & Plant X & & 285 & & & 96.4 & 3.6 \\
\hline \multirow[t]{4}{*}{ Tumble Index } & Plant Y-bad TI & Industrial & 303 & & & 92.9 & 7.1 \\
\hline & Plant Y-good TI & I pellet & 287 & & & 92.6 & 7.4 \\
\hline & Plant Z-bad TI & samples & 257 & & & 95.5 & 4.6 \\
\hline & Plant Z-good TI & & 269 & & & 96.2 & 3.8 \\
\hline Firing & $1050{ }^{\circ} \mathrm{C}$ & Laboratory & 62 & & & 72.5 & 27.5 \\
\hline \multirow[t]{2}{*}{ Temperature } & $1200{ }^{\circ} \mathrm{C}$ & pellet & 164 & & & 88.1 & 11.9 \\
\hline & $1280^{\circ} \mathrm{C}$ & samples & 313 & & & 96.3 & 3.7 \\
\hline \multirow[t]{3}{*}{ Excess Coke } & $80 \% \mathrm{HME}$ & Laboratory & 346 & 97 & 2.9 & & \\
\hline & 90\% HME & pellet & 272 & 96.3 & 3.5 & & \\
\hline & $90 \%+$ adj. fire & samples & 310 & 96.7 & 3.2 & & \\
\hline \multirow[t]{3}{*}{ Excess Coke } & $75 \% \mathrm{HME}$ & Laboratory & 366 & 97.2 & 2.7 & & \\
\hline & 107\% HME & pellet & 187 & 97 & 2.7 & & \\
\hline & $107 \%+$ adj. fire & samples & 230 & 96.6 & 3.1 & & \\
\hline
\end{tabular}



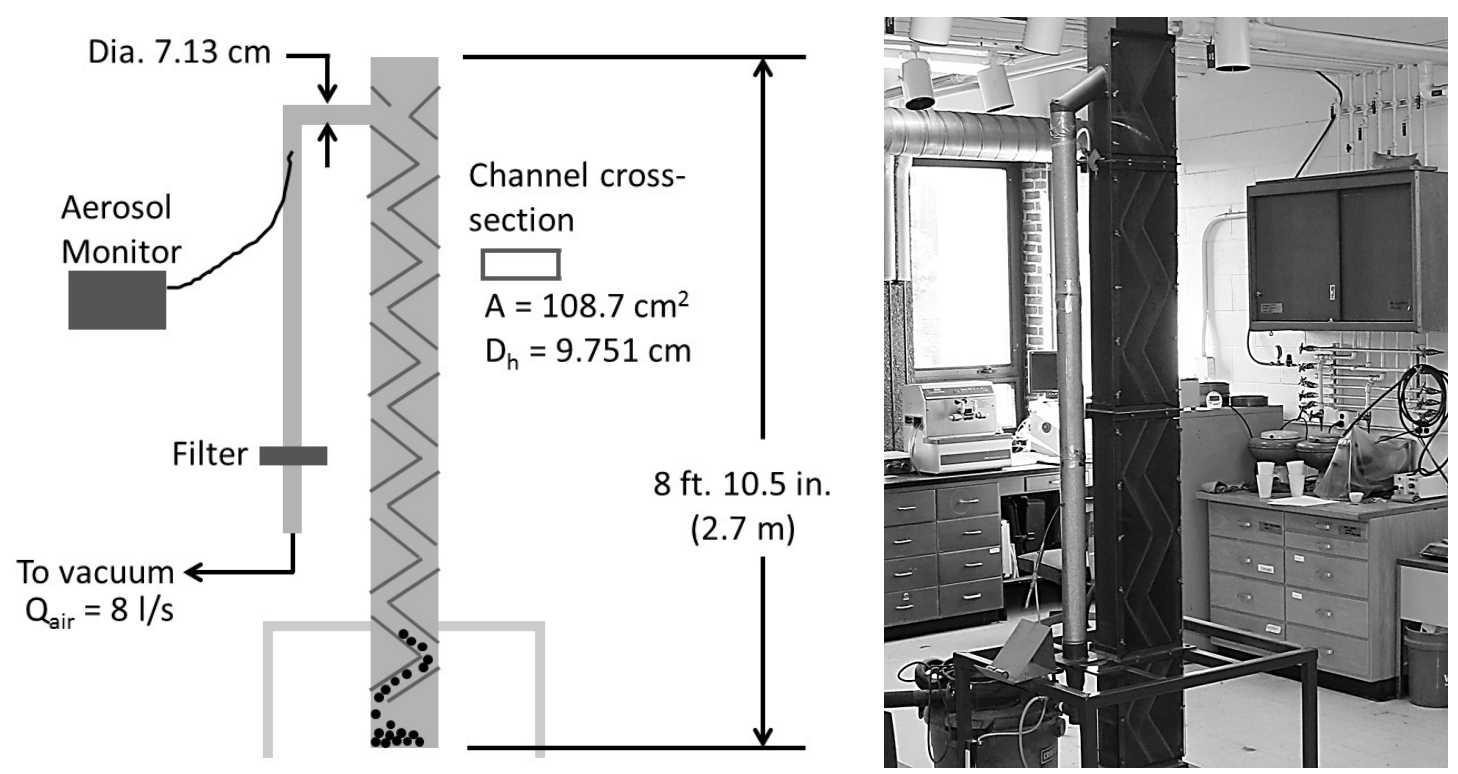

Figure 3 MTU dust tower schematic (I) and laboratory experimental set-up (r).

\subsubsection{Effects of experimental parameters on cumulative mass measurements}

Preliminary experiments were conducted to determine effects of dust tower variables on the cumulative mass of airborne particles collected. Variables tested were sample quantity $(0.4,1.0,1.7 \mathrm{~kg})$; number of drops (1-5); and sample pre-cleaning (as-received, blown off with compressed air). All samples were dried $\left(150{ }^{\circ} \mathrm{C}\right)$ and screened $(+1 / 4$ in. $/ 6.4 \mathrm{~mm})$ before dropping through the tower. Pellet samples used for preliminary experiments were Pellet chemistry - Plant E, as a large supply was readily available.

Preliminary work showed a slight increase in the collected airborne mass when sample quantity increased. Airborne mass increased from 45 to $50 \mathrm{mg} / \mathrm{kg}$-drop at drop 1 when sample quantity increased from 0.4 to $1.7 \mathrm{~kg}$. Mass per drop decreased during drops 2 through 5 , and stabilized around $25-30 \mathrm{mg} / \mathrm{kg}$-drop. The minimal increase in airborne mass for larger sample quantities suggested pellet-pellet interaction was not a significant contributor of fine particles during dust tower testing. It had been expected that dropping increased quantities of pellets through the tower would increase airborne mass due to additional abrasive "events" between pellets. It appeared that fine particles were produced by pellet surface degradation only during interactions with the impact plates. 


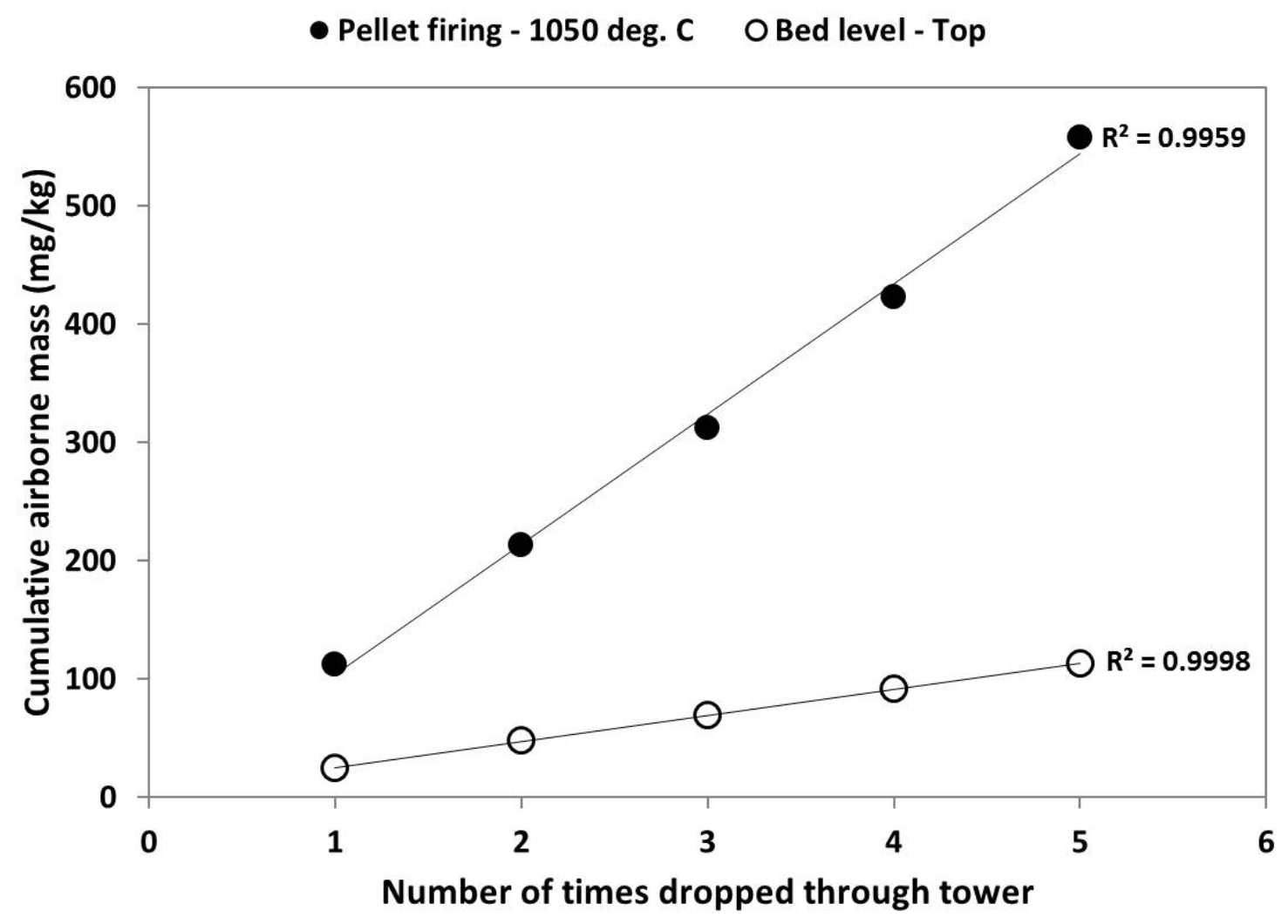

Figure 4 Cumulative airborne mass collected after each drop through the dust tower.

Additional tests conducted at constant sample size $(1 \mathrm{~kg})$ and varying pellet diameters resulted in a direct correlation between change in surface area and change in airborne mass collected. Decreases in particle diameter led to larger cumulative airborne mass measurements. Particulate matter generation occurred by abrasion, which is a surface area phenomenon, in the dust tower.

Pellets, dried at $150{ }^{\circ} \mathrm{C}$ and screened to $+1 / 4 \mathrm{in} . / 6.4 \mathrm{~mm}$, were tested as-received and after a "cleaning" procedure. During cleaning, dried, pre-screened pellets were blown with compressed air for $30 \mathrm{~s}$. The cleaning procedure reduced cumulative airborne mass from $60-65 \mathrm{mg} / \mathrm{kg}$ to $20-25 \mathrm{mg} / \mathrm{kg}$. Cleaning pellets with compressed air reduced cumulative airborne mass to similar stabilization values as observed after multiple drops using asreceived pellets. Taken together, these observations suggested that handling prior to and during sample preparation was an important contributor to dust formation and its effects should be minimized when testing pellets for their propensity to produce dust. 
The final procedure used to evaluate the 25 types of pellets in this study included drying $\left(150{ }^{\circ} \mathrm{C}\right)$, screening $(+1 / 4 \mathrm{in} . / 6.4 \mathrm{~mm})$, and cleaning with compressed air for $30 \mathrm{~s}$. This resulted in a reproducible measurement of cumulative airborne mass that linearly increased with number of drops through the tower (Figure 4). In the Results section, cumulative airborne mass measurements are reported after 5 drops through the tower.

\subsection{Results and discussion}

Direct measurements of cumulative airborne mass produced during pellet handling were measured using MTU's dust tower. Airborne particles were concentrated into a small duct and filtered out of the air stream by a filter paper. Changes in filter paper weight were attributed to airborne particles. Cumulative airborne mass for each pellet type is shown in Figure 5 a-f. No trends were observed using the aerosol monitor: deviations in the $\mathrm{PM}_{10}$ measurement were of the same order of magnitude as the measurements.

\subsubsection{Effects of Bed Level}

In Straight-Grate (or Traveling Grate) furnaces, there is a temperature gradient between pellets at different bed depths. The temperature gradient can lead to variations in pellet physical and metallurgical quality with depth, or level, in the pellet bed. Oja (2013) showed bottom-of-bed pellets had a greater quantity of weak pellets (\% - $300 \mathrm{lbs})$ and a lower tumble index $(\%+6.4 \mathrm{~mm})$ compared to the middle and top layers, while the top-of-bed pellets were brittle (very wide deviation in the percent $-6.4 \mathrm{~mm}$ material produced by 10 $50 \mathrm{ft}$. drops) compared to the middle and bottom layers. Gudenau et al., (1985) showed that pellet quality deviations due to bed level were pronounced in pellets larger than $10 \mathrm{~mm}$ in diameters. They explained that larger pellets in the bottom layer were insufficiently fired, and larger pellets in general require longer induration times.

Here, cumulative airborne mass collected during Bed Level pellet handling ranged insignificantly from 103 to $123 \mathrm{mg} / \mathrm{kg}$ (Figure 5-a). The pellets from each of the bed layers appeared to be well fired as evidenced by constant compression strengths ( $300 \mathrm{~kg} / \mathrm{pellet})$ and low abrasion indices around $3 \%-0.5 \mathrm{~mm}$. The hearth layer pellets had a slightly higher abrasion index $(3.7 \%-0.5 \mathrm{~mm})$ than the other layers; although, this is not currently explained. Hearth layer pellets are recycled through the furnace and undergo a reheating process. Pilot scale studies have shown that repeatedly heating pellets to firing temperatures does not degrade their abrasion index (Martinovic et al., 1998). 

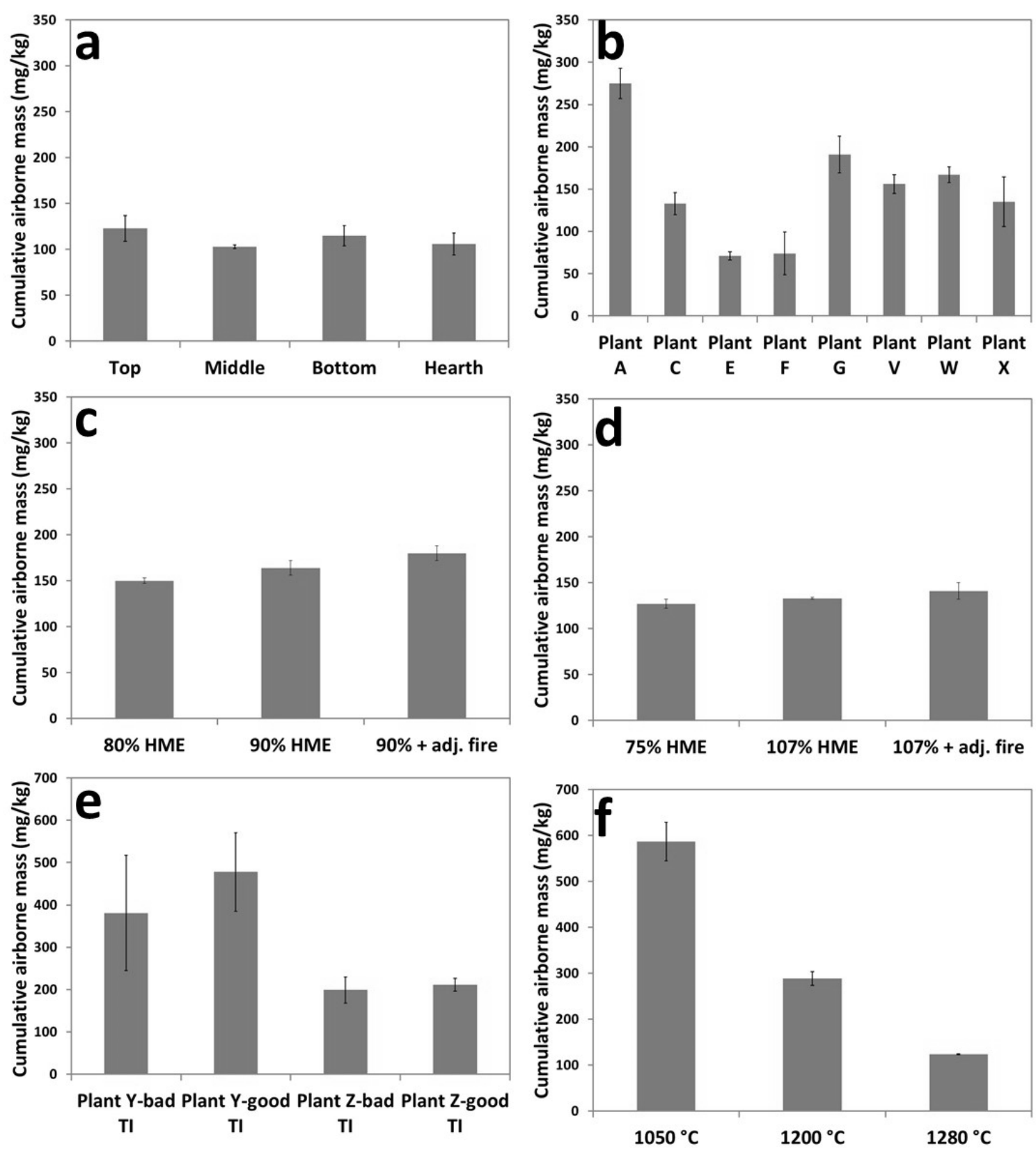

Figure 5 Cumulative airborne mass for each pellet type tested. Pellet samples are a) bed level; b) pellet chemistry; c) excess coke 1; d) excess coke 2; e) tumble testing; and f) firing temperature. Cumulative airborne mass reported after 5 drops through tower. "Tl" indicates Tumble Index. "HME" indicates heat of magnetite equivalent, and represents the quantity of coke breeze added to green-balls. "Adj. fire" indicates an adjustment to the pot-grate firing procedure. 


\subsubsection{Effects of Pellet Chemistry}

Cumulative airborne mass collected while handling the Pellet Chemistry samples generally ranged from 71 to $167 \mathrm{mg} / \mathrm{kg}$ (Figure 5-b). One sample (Plant A) produced a significantly larger quantity of airborne material, $275 \mathrm{mg} / \mathrm{kg}$, possibly resulting from poor firing as evidenced by low compressive strength $(178 \mathrm{~kg} / \mathrm{pellet})$ and high abrasion index $(7.2 \%$ $0.5 \mathrm{~mm}$ ). Each pellet chemistry sample represents a separate pelletizing plant - ore type and nature; gangue and flux levels; and binder type and quantity all vary from sample to sample.

\subsubsection{Effects of Excess Coke}

Coke breeze and other carbon-rich solid fuels are used as an internal heat source during pellet firing. The internal fuel can reduce fuel consumption and ring build-up in the induration furnace (Hanninen et al., 2003; Umadevi et al., 2008) and produce a more uniform pellet microstructure (Godin and Wilhelmy, 2008). Hasenack (1977) reports that coke breeze additions should supply 130 percent of the heat obtainable from magnetite oxidation, and total doses be less than $1.5 \%$.

For each of the Excess Coke samples (Figure 5-c,d), increasing percent HME (increasing coke breeze content) from 80 to 90 and from 75 to $107 \%$ lowered pellet compression strength by more than $20 \%$. Decreased compression strength with higher coke breeze levels has been reported by others (Hanninen et al., 2003). By adjusting pellet firing, some strength was recovered. In general, increased percent HME resulted in higher abrasion indices for both sets of excess coke samples, and higher levels of airborne mass. The lower basicity samples (Figure 5-d) were more abrasion resistant and produced less airborne material, suggesting chemistry was more influential than coke breeze addition.

\subsubsection{Tumble Test pellets}

Two pellet chemistries were provided, each with a "good" and "bad" Tumble Index as designated by the pellet supplier. For both pellet chemistries, there was no significant difference in cumulative airborne mass between the good and bad samples (Figure 5-e). However, Plant Y pellets produced 380-478 mg/kg while Plant Z pellets produced 199-211 $\mathrm{mg} / \mathrm{kg}$, suggesting chemistry strongly influenced pellet degradation and eventual pellet dustiness.

\subsubsection{Effects of Pellet Firing Temperature}

Induration temperature significantly affects pellet quality. Increasing induration temperature is understood to consolidate the pellet structure and reduce porosity. Grains begin necking and bridging and crystal growth occurs, often at a temperature near 1200$1250^{\circ} \mathrm{C}$; although, this depends on the ore and additives used. 
The firing temperature pellet samples were indurated at three temperatures ranging from a typical firing temperature $\left(1280{ }^{\circ} \mathrm{C}\right)$ to a preheat temperature $\left(1050{ }^{\circ} \mathrm{C}\right)$. The results showed that cumulative airborne mass decreased linearly with firing temperature (Figure 5-f), and there was a linear correlation between AI and cumulative airborne mass for these samples. Overall, the firing temperature results showed a nearly 21 percent increase in dustiness for every percent decrease in firing temperature - based on the typical firing temperature of $1280^{\circ} \mathrm{C}$. Lowering the firing temperature from 1280 to $1200^{\circ} \mathrm{C}$ significantly lowered compression strength (313 to $164 \mathrm{~kg}$ ), and increased the Abrasion Index (3.7 to $11.9 \%$ ) and cumulative airborne mass (124 to $289 \mathrm{mg} / \mathrm{kg}$ ).

These results show that insufficient firing appears to be a major cause for increased generation of fine particles and dust, and there is a critical firing temperature required to achieve good induration. Pellet quality is very sensitive to temperature below the critical temperature. The results also suggest that AI can be used to indicate the propensity for very high levels of dust.

\subsubsection{Comparison between Cumulative Airborne Mass and Abrasion Index}

A major goal of this research project was to determine if iron ore pellet dustiness correlates to abrasion indices, as observed in the three firing temperature samples. The abrasion index is a common pellet quality index used around the world; potentially gleaning more information from a single tumble test would be useful for pellet producers. Figure 6illustrates what appears to be, at first glance, a strong correlation between cumulative airborne mass and abrasion index $\left(\mathrm{R}^{2}=0.69\right)$ for all samples tested in this study. Note that in Figure 6, two data points exceeding an AI of $10 \%$ are not shown for graphical clarity.

The correlation may be explained by effects of incomplete firing on pellet quality which essentially led to four points on the cumulative airborne mass vs AI curve (at $\mathrm{AI}<5 \%, 7$ $\%, 11 \%$, and $27.5 \%$ ). Pellets originate from a powder material and will easily degrade back to individual particles and weakly bonded fragments if the induration process and its associated phenomena (oxidation and recrystallization, melt formation, pore size and porosity reduction and grain growth) are not complete.

The dominant effect of pellet firing on dustiness was supported by only considering pellet types with abrasion indices less than five percent $-0.5 \mathrm{~mm}$. In effect, five pellet samples were removed from the analysis (Tumble Test-Plant Y, Pellet Firing 1050 and $1200{ }^{\circ} \mathrm{C}$, and Pellet Chemistry-Plant A). Removing those samples resulted in a very weak correlation between cumulative airborne mass and abrasion index, with an $\mathrm{R}^{2}$ value of 0.22 . In other words, variations in abrasion index did not explain variations in cumulative airborne mass for good-quality pellets. 


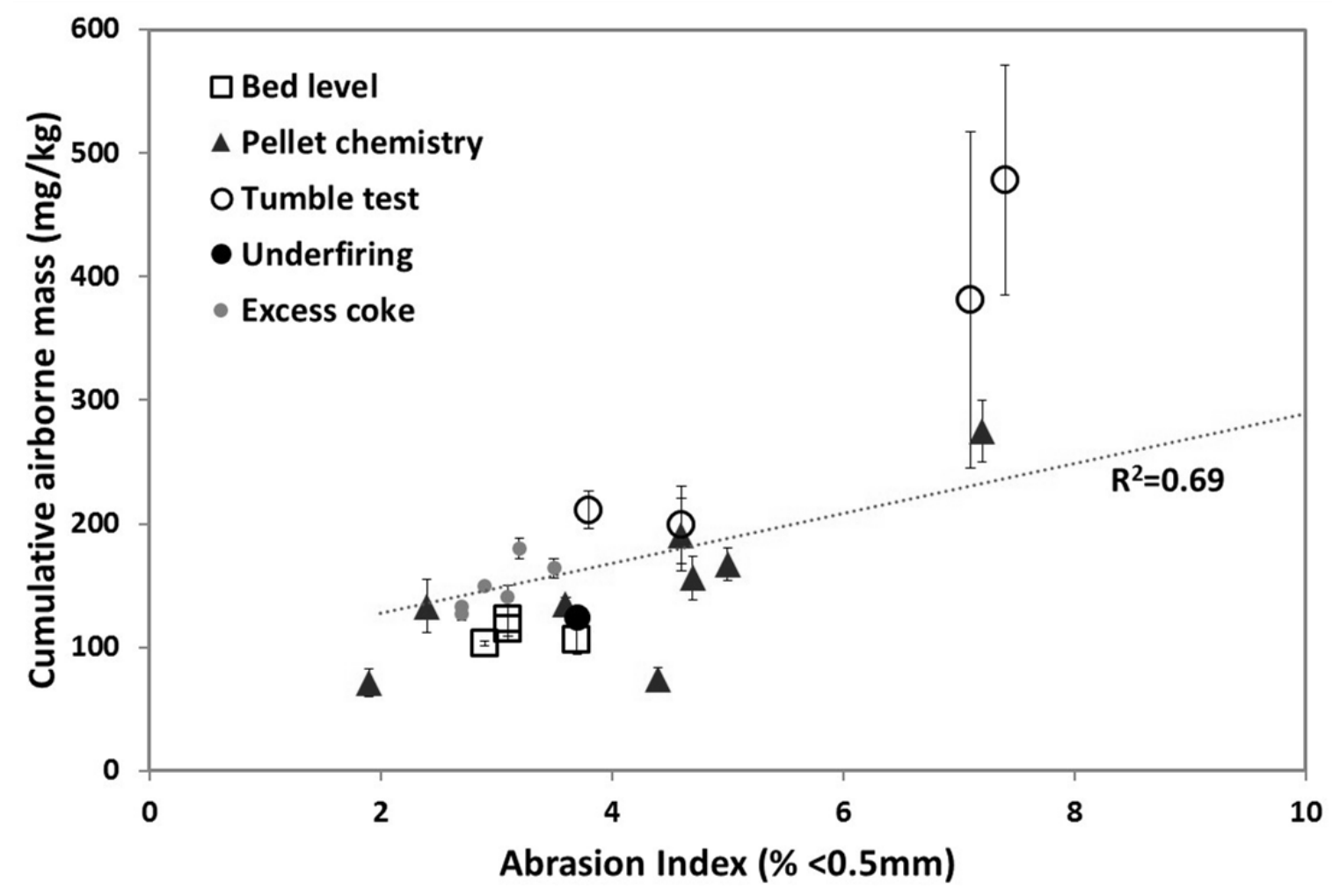

Figure 6 Correlation between total cumulative dust $(\mathrm{mg} / \mathrm{kg})$ and Abrasion Index $(\%<0.5 \mathrm{~mm}$ ). Two data points beyond $10 \%$ Al (firing temperature 1050 and 1200 $\left.{ }^{\circ} \mathrm{C}\right)$ have been excluded for clarity.

Although not quantified, it was thought that the poor correlation between cumulative airborne mass and abrasion index may in part be explained by the nature of the particulate matter produced by each type of pellet during degradation, and by surface roughness effects.

\subsubsection{Visual examination of dust particles}

The cumulative airborne masses from select samples were visualized under SEM. Loose particles that had collected on the top of the filter paper were deposited on conductive tape and placed on an aluminum SEM stub. A small segment $(1 \mathrm{~cm} \mathrm{x} 1 \mathrm{~cm})$ of each filter paper was removed and placed on a stub as well. Samples were carbon coated and visualized under SEM. Representative coarse particles, shown in Figure 7-a, illustrate the wide range of airborne particles and sizes produced and collected during this study. 


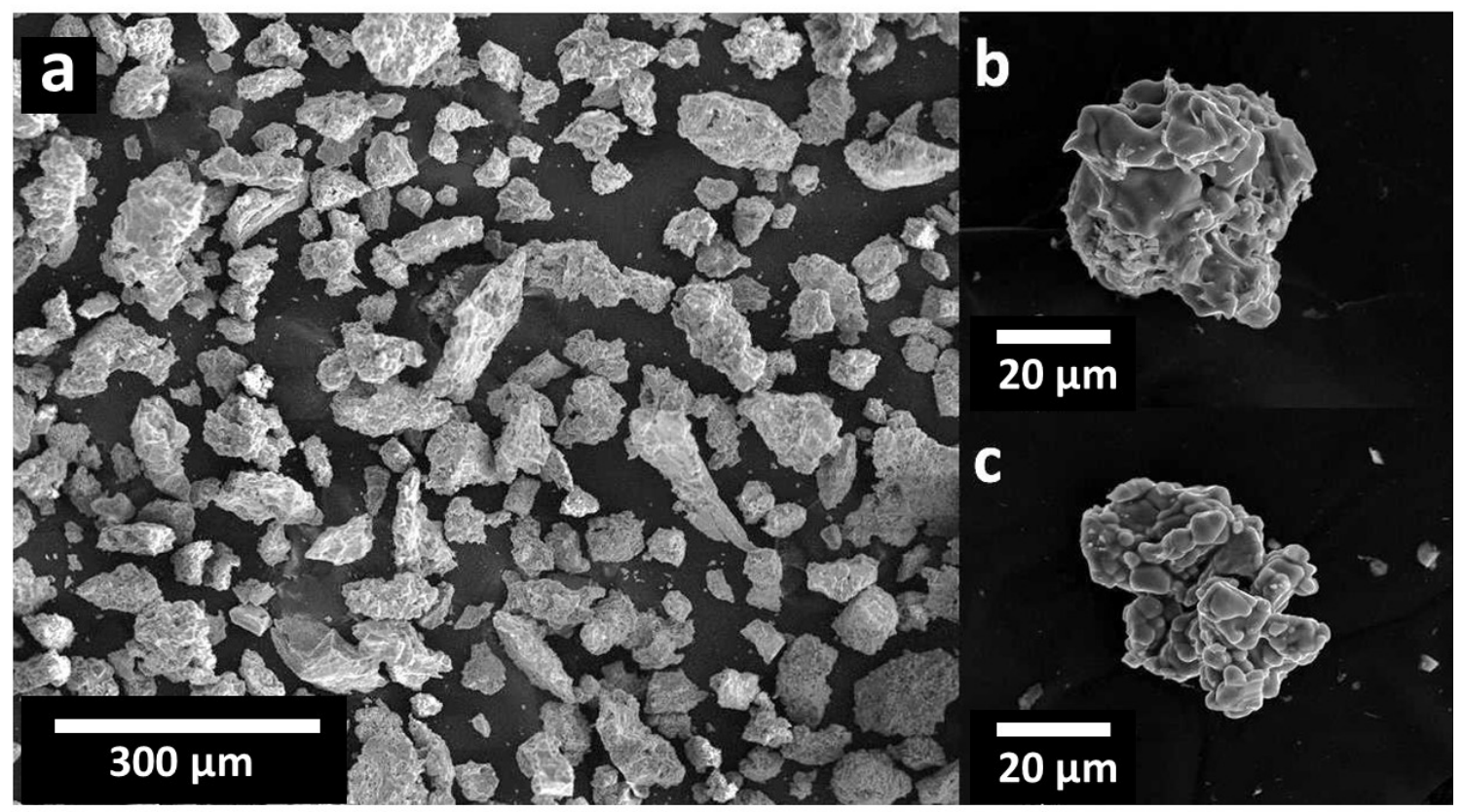

Figure 7 SEM micrographs of airborne particles collected while handling various types of pellets: a) Pellet Chemistry-Condition E, scale bar $300 \mu \mathrm{m}$; b) Pellet Chemistry-Condition F, scale bar $20 \mu \mathrm{m}$; c) Pellet Chemistry-Condition C, scale bar $20 \mu \mathrm{m}$.

Considering a typical hematite density of $5000 \mathrm{~kg} / \mathrm{m}^{3}$, the cumulative airborne mass measurement may best be considered as Total Suspended Particulates, although some particles were much larger than traditional dust particles. Using measured airflow data in the dust tower, it was calculated that particles up to an aerodynamic diameter of $200 \mu \mathrm{m}$ $\left(\mathrm{PM}_{200}\right)$ may be collected and reported in the cumulative airborne mass measurement. The presence of large particles and fragments may tend to dominate this measurement and effectively mask differences in $\mathrm{PM}_{10}$ generation between samples.

In general, particles ranged from smaller than $1.0 \mu \mathrm{m}$ to $200 \mu \mathrm{m}$ in diameter. The average and maximum size, as well as the particle fracture surfaces, differed between pellet types. Coarse particles appeared to consist of the original ore particles bonded together into an aggregate structure. Figure 7-b shows a fragment from a bentonite-bonded pellet, which appears to have sharp conchoidal features, reminiscent of glassy or brittle fracture. Figure 7-c shows an airborne particle originating from pellets agglomerated using an organic binder. In this case, the sharp features were absent. The average and maximum diameters of particles from Plants $\mathrm{F}$ and $\mathrm{C}$ (two measurements from 60 individual particle for each) were measured to be 73 and $190 \mu \mathrm{m}$, and 56 and $157 \mu \mathrm{m}$, respectively. These results 
suggest that the abrasion product size distributions vary between pellet types, which is supported by Copeland and Kawatra (2005).

\subsubsection{Potential effects of surface roughness}

Total cumulative airborne mass was generally less than $500 \mathrm{mg} / \mathrm{kg}$ pellets after 5 drops through the tower. Due to the small quantities of mass collected during each test, it may be argued that dustiness rankings may have been sensitive to surface effects or variations in surface roughness. Surface roughness effects were observed by Sivrikaya and Arol (2013) in a concurrent study using the dust tower. They evaluated the effects of different organicinorganic binder combinations on iron ore pellet dustiness. In those trials, pellet dustiness increased with visually observed increases in pellet surface roughness. Here, surface roughness was relatively consistent, except for between a few pellet chemistry samples. Even considering this potential complicating factor, pellet firing temperature was shown to be the most important factor affecting pellet dustiness.

\subsection{Conclusions}

With increasing emphasis on reducing particulate emissions and increased levels of governmental regulations, iron ore pellet producers may need to understand dominant factors contributing to iron ore pellet dustiness. This preliminary investigation directly measured cumulative airborne mass produced while handling 25 types of laboratory and industrial iron ore pellets. Major variables evaluated during this study included bed level, pellet chemistry, firing temperature, excess coke additions, and a comparison between "good" and "bad" tumble test pellets (as designated by the pellet supplier). Three major conclusions drawn from this study are as follows:

- Two variables significantly contributed to the dustiness of iron ore pellets: pellet firing temperature and pellet chemistry. Cumulative airborne mass decreased from 587 to $124 \mathrm{mg} / \mathrm{kg}$ when firing temperature increased from 1050 to $1280{ }^{\circ} \mathrm{C}$. Cumulative airborne mass collected while handling the Pellet Chemistry samples generally ranged from $71-167 \mathrm{mg} / \mathrm{kg}$, with each sample representing a separate industrial pellet plant.

- Cumulative airborne mass correlated to abrasion index when considering all 25 types of pellets tested in this study $\left(\mathrm{R}^{2}=0.69\right)$. The correlation was explained by the dominant effects of under-firing pellets, which essentially led to four points on the cumulative airborne mass vs AI curve (at $\mathrm{AI}<5 \%, 7 \%, 11 \%$, and $27.5 \%$ ). Underfired pellets are weak and easily degrade during abrasion, producing a fine powder consisting of individual particles and aggregates similar in structure to the original pellet. Only considering pellets with an abrasion index $<5 \%-0.5 \mathrm{~mm}$ reduced the correlation coefficient to 0.22 . 
- Visually, the collected airborne particles appeared to consist of a wide range of shapes and sizes, which depended on the pellet type. The cumulative airborne mass measurement may have been dominated by the presence of large particles, effectively masking potential differences in $\mathrm{PM}_{10}$ generation between pellet types.

In summary, the work reported in Chapter 2 was conducted in order to determine if pellet dustiness correlates to the abrasion index. While no correlation existed using pellets collected from many sources, one may be present only using pellets from a single pellet plant.

Chapter 3 explains the relationship between AI and dust for good-quality pellets; and compares fines generation between pellets fired in Straight-Grate (Traveling Grate) and Grate-Kiln furnaces. 


\section{Effects of firing route and abrasion resistance on fines and dust generation ${ }^{2}$}

\subsection{Abstract}

Iron ore pellets degrade by impact and abrasion during their production and handling, which can lead to losses in material and product quality. This study was conducted in order to a) determine whether firing route (Straight-Grate or Grate-Kiln furnaces) affects pellet dustiness; and b) explain the relationship between Abrasion Index and pellet dustiness. Results showed that pellets fired in Straight Grate furnaces were less abrasion resistant than pellets fired in Grate Kiln furnaces. Fines generation rates for SG pellets were 3.5 times higher than for GK pellets. Iron ore concentrate type, pellet binder, and firing temperature all affect the quality and abrasion resistance of pellets. For poor quality pellets (AI $>5$ percent), AI can be used to indicate potentially high levels of dust. For good quality pellets (AI $<5$ percent), as AI decreases, the abrasion product fineness increases. This leads to a poor correlation between $\mathrm{AI}$ and $\mathrm{PM}_{10}$ for good quality pellets.

The results from Chapters 2 and 3 of this thesis suggest that material loss and levels of pellet dustiness may be significantly affected by pellet quality up to a certain point. Poorlyfired pellets will be dusty during handling and transportation, while well-fired pellets will generate less - but finer - material as their quality improves. This could lead to little observed changes in $\mathrm{PM}_{10}$ generation over a wide range of pellet quality. Dust generation at each site would then depend on the quantity of material produced and their extent of handling.

\subsection{Introduction}

Iron ore pellets degrade by impact and abrasion during their production and handling. Depending on the type (impact or abrasion) and extent of breakage, different quantities of fine material are generated (Figure 8). The generation of iron ore pellet fines can lead to material loss and operational problems throughout the entire production and handling chain.

\footnotetext{
${ }^{2}$ Halt, J.A., and Kawatra, S.K., (2013) "Iron ore pellet dustiness Part II: Effects of firing route and abrasion resistance on fines and dust generation" Under Review
} 


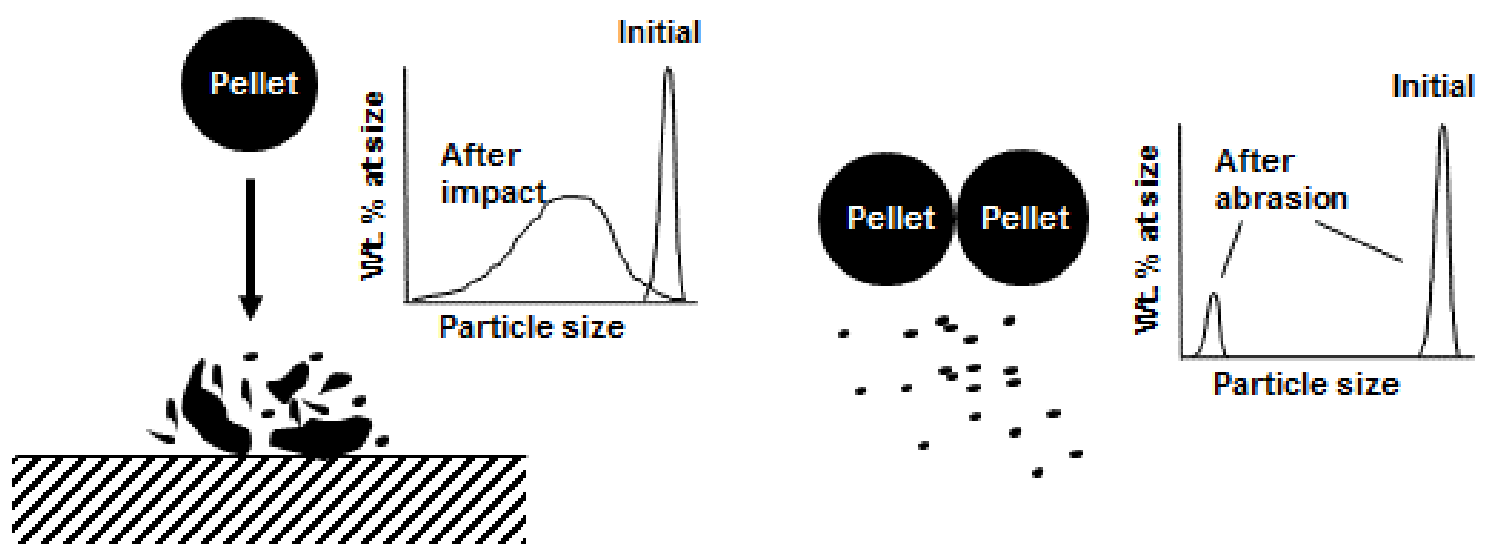

Figure 8 Pellet degradation by impact (left) and abrasion (right), and their resulting particle size distributions. Fragmentation produces a wide distribution. Abrasion produces a bimodal distribution that consists of the original coarse particles and very fine powder.

For example, inside of induration furnaces, dust particles from pellets and coal combustion deposit on furnace walls and degrade refractory liners (Jonsson et al., 2013). Pellet fines were reported to blind voids and lower the permeability in shaft furnaces, and increase coke consumption and reduce specific output during their operation (Fagerberg and Sandberg, 1973). For these, and potentially other reasons, pellet producers and consumers desire to know which processing and handling conditions minimize material loss issues.

In Chapter 2, we showed that high abrasion indices (AI), caused by insufficient pellet firing, lead to high levels of dust. However, for good quality pellets, there was no correlation between AI and dustiness. The purpose of this chapter was to investigate effects of firing route (Straight-Grate vs Grate-Kiln) on pellet dustiness, and explain the relationship between Abrasion Index and dust generation for good-quality pellets.

\subsection{Background}

\subsubsection{Iron ore pellet degradation}

Fagerberg and Sandberg (1973) reported how lump iron ore and pellets degrade under various handling conditions. Samples were subjected to 20 -meter high drop tests and repeated 2-meter drops, as well as the standard tumble drum test for iron ore pellets. Fines were defined as the $-0.5 \mathrm{~mm}$ fraction, as is common in the iron ore industry. The authors concluded that in general, reducing the number of drops and the total drop height, and screening out material closely sized to $0.5 \mathrm{~mm}$ greatly reduced fines generation. Important material variables affecting fines generation were mechanical strength, density, size, size 
distribution and initial fines content. Hard materials such as well-fired pellets resisted drops without significant breakage and generated fines "almost entirely by abrasion". However, we believe that many actions taken to reduce pellet breakage by impact will increase occurrences of abrasion.

Copeland and Kawatra (2005) showed that different types of iron ore pellets generated varying quantities of fine particles $(<600 \mu \mathrm{m})$ using a set of mechanically agitated screens. Fines generation rate varied from $0.21-0.88 \mathrm{~g} / \mathrm{kg}$-min ( $1 \mathrm{~kg}$ sample; $15 \mathrm{~min}$ ), and the size consist of the fines ranged from 23-43 percent passing $10 \mu \mathrm{m}$. They suggested pellet firing route - Straight Grate (SG) or Grate Kiln (GK) - could be an influential factor. Sivrikaya and Arol (2013) showed that pellet dustiness can be reduced by using binders. All airborne material collected during their dust tower study was less than 100 micrometers in diameter, and the quantity of particulates finer than 10 micrometers ranged from 30-40 percent for pellets made with bentonite, organic, and calcined-colemanite binders.

\subsubsection{Aerodynamic diameter}

The aerodynamic diameter is used to explain the behavior of dust particles in air. It is defined as the diameter of an ideal, equivalent, spherical particle with a density of $1 \mathrm{~g} / \mathrm{cm}^{3}$ that has an identical settling velocity as the particle of interest (Baron and Willeke, 2001). Aerodynamic diameter $\left(d_{a}\right)$ is influenced by particle size $\left(d_{p}\right)$ and density $\left(\rho_{p}\right)$ as shown in Equation 1, which neglects a correction factor for non-spherical particle shapes.

$$
d_{a}=d_{p}\left(\frac{\rho_{p}}{\rho_{a}}\right)^{1 / 2}
$$

Equation 1

In Equation 1, $\rho_{\mathrm{p}}$ is the aerodynamic density $\left(1 \mathrm{~g} / \mathrm{cm}^{3}\right)$. Equation 1 is relevant for the particle sizes of interest in this study $\left(\mathrm{d}_{\mathrm{p}}>1 \mu \mathrm{m}\right)$. Thus if the density and spherical diameter of particles generated by abrasion are known, it follows that the aerodynamic diameter can be estimated. Deviations away from spherical shapes tend to increase the aerodynamic diameter. 
Table 2 Industrial pellet characterization. Table notes: S.G. = Specific Gravity; Screen size distribution determined by sieve analysis. Pellet S.G. determined following ASTM C914-09

\begin{tabular}{cccccccc}
\hline Pellet & Pellet & Powder & Pellet & Failure & \multicolumn{3}{c}{ Pellet screen size distribution - wt \% } \\
Plant & S.G. & S.G. & Porosity & Load (N) & $\mathbf{6 . 4 \times 9 . 5 ~} \mathbf{~ m m}$ & $\mathbf{9 . 5 \times 1 2 . 7 ~} \mathbf{~ m m ~}$ & $\mathbf{1 2 . 7 \times 1 5 . 9 ~} \mathbf{~ m m}$ \\
\hline A & 3.54 & 4.66 & 0.24 & 1750 & 5.2 & 89.4 & 5.4 \\
C & 3.85 & 4.78 & 0.19 & 3160 & 19.8 & 79.0 & 1.3 \\
E & 3.38 & 4.59 & 0.26 & 2000 & 5.8 & 92.0 & 2.2 \\
F & 3.34 & 4.70 & 0.29 & 2110 & 16.6 & 82.4 & 1.0 \\
G & 3.48 & 4.69 & 0.26 & 2340 & 10.7 & 74.7 & 14.6 \\
\hline
\end{tabular}

\subsection{3 $P M_{10}$}

Particulate matter with aerodynamic diameters equal to or less than ten micrometers are called $\mathrm{PM}_{10}$. These are considered to be coarse, inhalable particles, and their emissions may be regulated. In the Results and Discussion herein, we denote $\mathrm{PM}_{10}$ and finer as dust. Using Equation 1 and a solid particle density of $4.25 \mathrm{~g} / \mathrm{cm}^{3}$ (typical value for powdered iron concentrate), particles behaving as $\mathrm{PM}_{10}$ would visually appear to have diameters $\left(\mathrm{d}_{\mathrm{p}}\right)$ less than $4.85 \mu \mathrm{m}$. Particles with $10 \mathrm{um}$ diameter would be characterized with an aerodynamic diameter of $20.62 \mu \mathrm{m}$.

\subsection{Materials and Experimental Methods}

\subsubsection{Materials}

Iron ore pellets were made in the laboratory from iron ore concentrates and commercially available binders, and compared to five industrial pellet types.

\subsubsection{Laboratory pellet materials}

Two different iron ore concentrates were used to make pellets. Concentrate $\mathrm{D}$ was a fluxed, magnetite $\left(\mathrm{Fe}_{3} \mathrm{O}_{4}\right)$ concentrate ground (at the plant) to 80 percent passing $49 \mu \mathrm{m}$. The main gangue mineral was $\mathrm{SiO}_{2}$. Concentrate $\mathrm{F}$ was a fluxed, hematite $\left(\mathrm{Fe}_{2} \mathrm{O}_{3}\right)$ concentrate ground (at the plant) to 80 percent passing $30 \mu \mathrm{m}$. Magnetite was present as a secondary iron mineral and $\mathrm{SiO}_{2}$ was the principal gangue component. Bulk concentrate samples were split into approximately $2.5 \mathrm{~kg}$ samples prior to agglomeration.

Bentonite clay was used as the standard binder. The sample had a PWA value of 1000, and an 80 percent particle passing size of $14.3 \mu \mathrm{m}$. 
Three types of organic binders were evaluated in this study: sodium carboxymethylcellulose (Na-CMC), cornstarch, and polyacrylamide (PA). The number of samples of each organic binder type tested during this study were as follows: cornstarch (1 sample); Na-CMC (3 samples); and PA (6 samples). The binders spanned a range of molecular weights, ionic contents and type and quantity of inorganic additive. Detailed binder characteristics were not provided due to their proprietary nature.

\subsubsection{Industrial pellets}

Five types of industrial iron ore pellets were analyzed during the pellet breakdown study, and were also used for comparison with the laboratory-made pellets (Table 2). The pellet samples represented dominant furnace types (SG and GK); binder types (bentonite and organic); and major ore types (hematite and magnetite) found in industry.

\subsubsection{Pellet breakdown procedure}

In order to compare fines generation rates from pellets fired in SG and GK furnaces, the method of Copeland and Kawatra (2005) was directly followed. In brief, pellet samples were dried $\left(105^{\circ} \mathrm{C} / 24 \mathrm{hrs}\right)$, screened $(+3$ mesh was retained), and $1 \mathrm{~kg}$ was weighed out and placed on top of a stack of sieves ( 3 mesh, 35 mesh, pan). The loaded sieves were covered and placed in a Tyler Rotap and agitated for $15 \mathrm{~min}$. The amount contained in each size fraction was recorded after the test. Fines generation rate is reported as the quantity of -35 mesh fines generated per minute $(\mathrm{g} / \mathrm{min})$. The particle size distribution of the fines fraction generated during pellet breakdown was determined for each pellet type. Our results were directly compared to previously published data (Copeland and Kawatra, 2005).

\subsubsection{Pellet-making procedure}

Green-balls were prepared following standard agglomeration procedures. In brief, moist iron ore concentrate samples were mixed with the desired binder quantity $(5 \mathrm{~min}$.), and agglomerated into $11.2 \times 12.7 \mathrm{~mm}$ balls by continually adding fresh feed and spritzing water into a rotating steel drum $(46 \mathrm{~cm}$ dia., $25 \mathrm{rpm})$. Green-balls were dried $\left(105^{\circ} \mathrm{C}, 24\right.$ $\mathrm{hr}$.) and fired at a predetermined temperature $(1 \mathrm{hr}$.) in a box furnace in air.

\subsubsection{Abrasion test procedure}

Abrasion resistances and dustiness potentials of granular and powdery materials are commonly determined by tumbling materials in a rotating drum (Bach, 2008; Gill, 2006; Pensis, 2010; Petavratzi, 2005). In this study, iron ore pellets were screened (+ $6.4 \mathrm{~mm}, 30$ s.) and blown off with compressed air before testing their abrasion resistance. One kilogram of pellets was placed in a cleaned drum $(203 \mathrm{~mm}$ dia) and rotated at $57 \mathrm{rpm}$ for $5 \mathrm{~min}$. The drum had two antipodal lifters $1.2 \mathrm{~cm}$ wide. The lifters aided pellet mixing (instead of lifting-dropping pellets) due to their narrowness. 


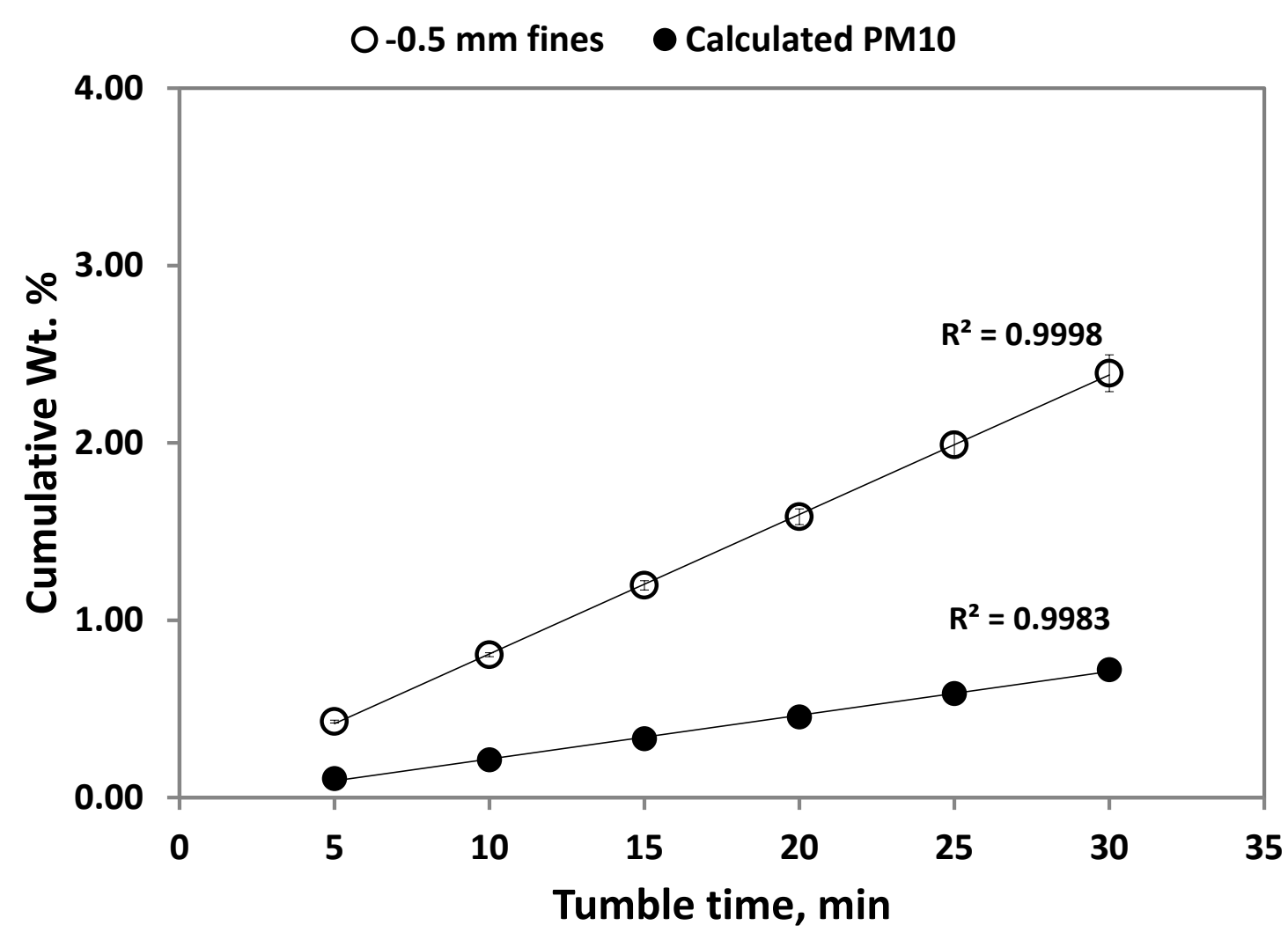

Figure 9 Procedure for calculating the quantity of $P M_{10}$ produced during abrasion. $P M_{10}$ percentiles from each sample were multiplied by the percentage of $-0.5 \mathrm{~mm}$ fines produced at that time interval. This example data shown is from type $C$ pellets.

After tumbling, the drum contents were removed, loaded onto a stack of sieves and hand sifted for $15 \mathrm{~s}$ into three size fractions $(+6.4 \mathrm{~mm}$ pellets, $-6.4+0.5 \mathrm{~mm}$ chips, and $-0.5 \mathrm{~mm}$ fines). The mass retained on each screen was recorded. Pellets $(+6.4 \mathrm{~mm})$ were placed back into the drum for further tumbling, while powder samples $(-0.5 \mathrm{~mm})$ were analyzed for size distribution and density. The Abrasion Index was defined as the quantity of -0.5 $\mathrm{mm}$ fines produced after 30 minutes, normalized to the initial pellet charge.

\subsubsection{Particle Size Distribution}

The size distribution of the abrasion powder was characterized using a Microtrac SRA 9200. Particle size distributions (PSD) were determined for the 5, 15 and 30 min. powder samples. PSD were fit using a log-normal function, which described the data well. 


\subsubsection{Powder density}

Powder density was determined using specific gravity bottles. The 10, 20 and $25 \mathrm{~min}$. powder samples were combined and mixed together to provide a composite sample for each type of pellet. Consequently, powder density was assumed to be constant with respect to abrasion time and particle size.

\subsubsection{Calculating the quantity of $P M_{10}$ generated during abrasion}

We calculated the quantity of $\mathrm{PM}_{10}$ produced during abrasion as follows. The particle size distribution for each time interval, measured by laser diffraction, was "shifted" following Equation 1 to produce an aerodynamic size distribution. The percentile passing ten micrometers was recorded as the $\mathrm{PM}_{10}$ level at that time. Using the mass of powder produced during each interval, and the percent $\mathrm{PM}_{10}$, the mass of $\mathrm{PM}_{10}$ was calculated for each time interval. A representative cumulative weight percent $\mathrm{PM}_{10}$ curve for Plant $\mathrm{C}$ pellets is shown in Figure 9. The cumulative weight percent $\mathrm{PM}_{10}$ calculation was more sensitive to changes in the particle size distribution than the powder density.

\subsection{Results and Discussion}

\subsubsection{Breakdown of iron ore concentrate pellets}

We determined the fines generation rates for pellets fired in Straight Grate (SG) and Grate Kiln (GK) furnaces following the method of Copeland and Kawatra (2005). The results are presented in Figure 10. As previously suggested, and confirmed herein, there is a significant difference between fines generation rates for pellets indurated in SG and GK furnaces. On average, the fines generation rate for pellets indurated in SG furnaces was 3.5 times higher than for GK indurated pellets. Although we do not clearly understand why SG furnaces produce dustier pellets than GK furnaces, there may be a number of potential factors. Several possibilities are discussed below.

In horizontal SG (or Traveling Grate) furnaces, a temperature gradient across the pellet bed can lead to variations in pellet physical and metallurgical quality with depth. In a pilot scale study using a pot-grate furnace, Oja (2013) showed that pellets fired on the bottom of the bed had a greater percentage of weak pellets $(\%-300 \mathrm{lbs})$ and a lower tumble index $(\%+$ $6.4 \mathrm{~mm}$ ) compared pellets located in the top and middle layers. Concurrently, the top-most pellets were brittle, as indicated by a very wide deviation in the percent $-6.4 \mathrm{~mm}$ material produced by 10-50 ft. drops, compared to pellets from the middle and bottom layers in the pot. 


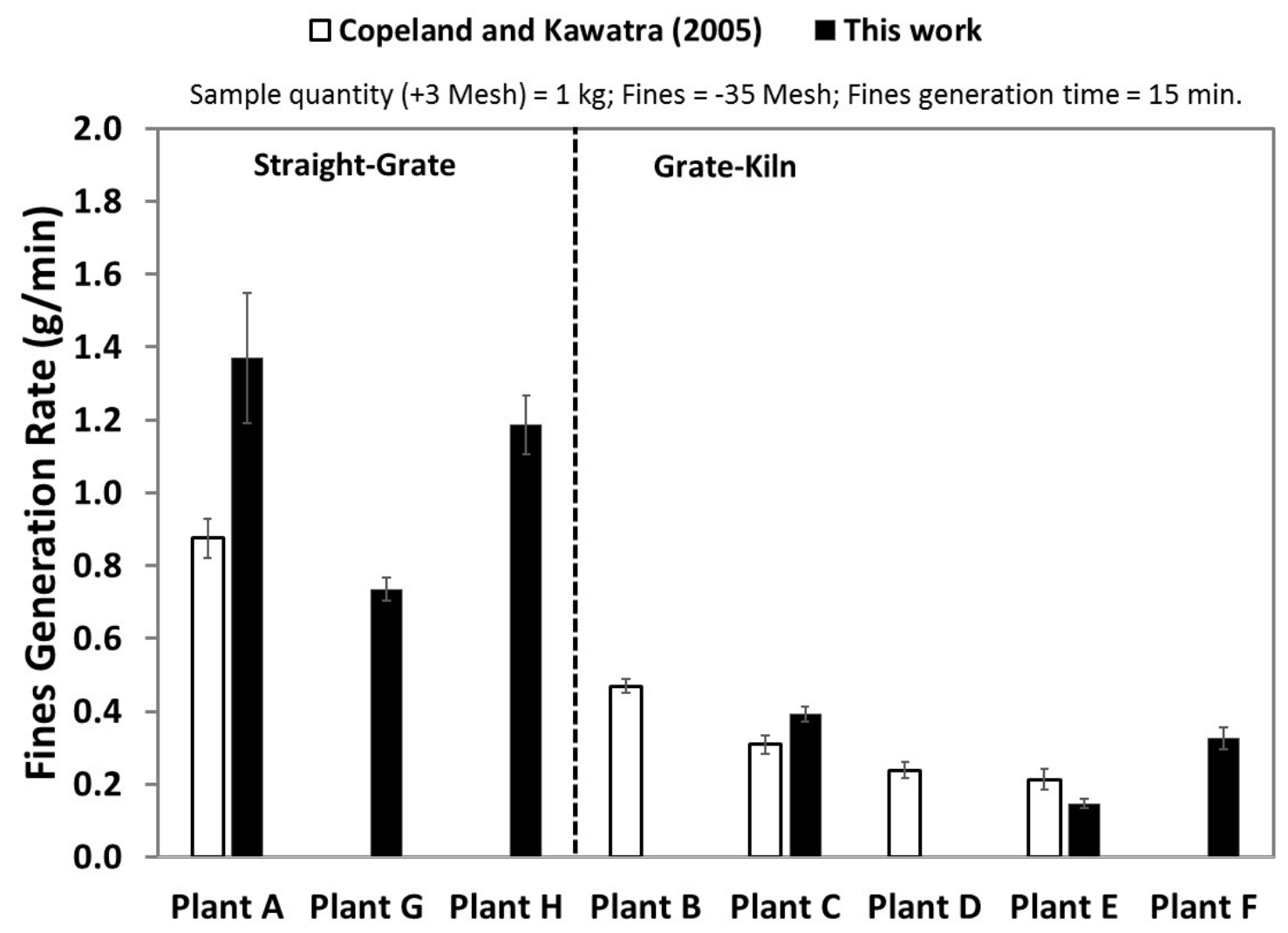

Figure 10 Fines generation rate for industrial pellets fired in SG and GK furnaces. Fines were generated by agitating one kilogram of +3 mesh pellets using a Tyler Rotap for 15 minutes. Fines were defined as the quantity of -35 mesh material produced during the test. The errors bars represent the standard deviations of 4 measurements for each sample.

Gudenau et al., (1985) also showed that pellet quality deviated due to bed level. Furthermore, the deviations were pronounced in the larger-sized pellets $(>10 \mathrm{~mm}$ diameter). They explained that larger pellets in the bottom layer were insufficiently fired, and increasing pellet diameters requires increasing firing times for complete induration. Consequently, the SG furnace pellet samples may have had larger quantities of insufficiently fired pellets, leading to higher levels of fines.

If temperature gradients and under-firing were the dominant factor, it had been expected that the compression strengths of pellets indurated in SG furnaces would have a higher relative standard deviation (RSD) than GK indurated pellets. For pellets collected in this study, the RSD of compression strengths (pellets $9.5-12.7 \mathrm{~mm}$ in diameter) closely ranged from 10-16 percent for all pellet types. 


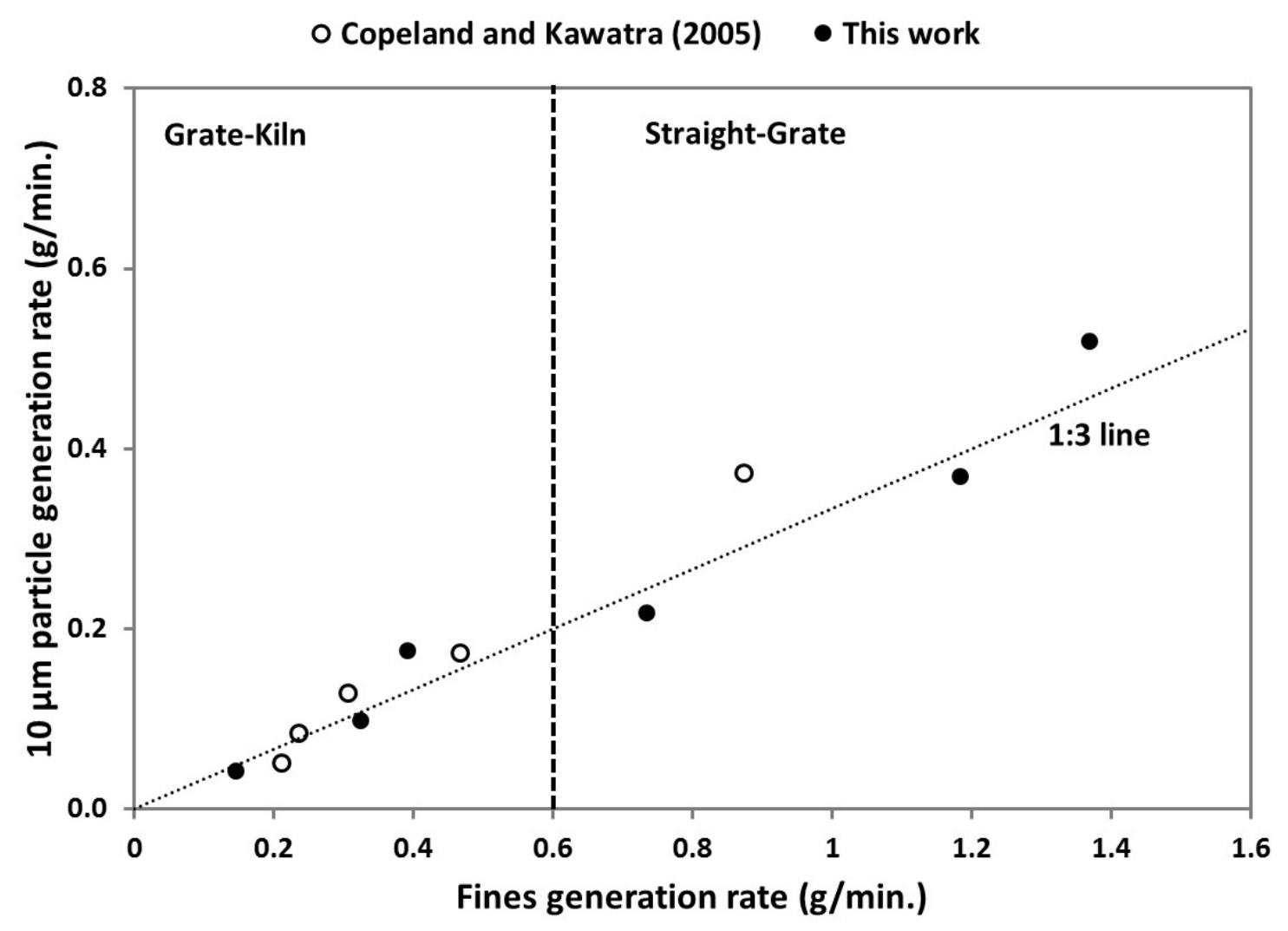

Figure 11 Generation rate of minus 10 micrometers particles as a function of fines generation rates. One kilogram of +3 mesh pellets were agitated using a Tyler Rotap for 15 minutes. Fines were defined as the quantity of -35 mesh material produced during the test. Particle size distributions were found using a Microtrac particle size analyzer.

In the GK, pellets are tumbled at high temperatures so all pellets are sintered to more similar levels. The tumbling action in the kiln, and the drop from the horizontal grate to the rotating kiln, may break weak pellets or remove surface irregularities that would contribute to fines and dust generation outside of the furnace. Rough pellets are thought to contribute to high abrasion indices, although no references have been found to support or weaken this argument.

\subsubsection{Size distribution of abrasion products}

The size consist of the minus 35 mesh degradation products ranged from 29-45 percent passing ten micrometers in diameter. As shown in Figure 11, there was a general correlation between the generation of fines ( -35 mesh) and the generation of minus 10 micrometer diameter particles. Altogether, these results suggest that the different firing 
routes could potentially explain the different levels of dustiness observed in good-quality pellets tested in Chapter 2, but they do not explain the poor correlation between abrasion index and pellet dustiness for those pellets.

As the abrasion product PSD varies with pellet type, as shown here and in Copeland and Kawatra (2005) and Sivrikaya and Arol (2013), it seems reasonable to assume that pellets could produce a large quantity of fines, whereby the particles have a large size consist, or a small quantity of fines composed of very fine particles. That would lead to similar levels of dust across a wide range of abrasion indices. Dust generation could be described as a function of the total quantity of fines generated, and their physical characteristics such as size distribution, density, and shape. This thought led us to examine how pellet abrasion resistance and the fines size distribution are related.

\subsubsection{Abrasion resistance of iron ore concentrate pellets}

The Abrasion Index and generation of $\mathrm{PM}_{10}$ for 45 types of iron ore pellets were determined by tumbling pellet samples for 30 minutes in a $203 \mathrm{~mm}$ dia. drum. Qualitatively, pellets were observed to become more rounded over time due to attrition, and became redder in appearance as the pellet surfaces were coated with fine particulate matter. Essentially only abrasion occurred in the drum, as the chips to fines ratio $(-6.4+0.5 \mathrm{~mm}:-0.5 \mathrm{~mm})$ was around five percent for each type of pellet.

The abrasion rate, taken as the natural log of the ratio between pellet weight and the initial pellet weight, was a first order rate process. First order abrasion rate processes (linear with respect to time) have been observed with other iron making materials, such as coke and model coke materials (Litster et al., 1986). Similar to observations by Fagerberg and Sandberg (1973) and Sivrikaya and Arol (2013), the abrasion rate did not correlate to compressive strength. This suggests that the abrasion mechanisms are strongly influenced by fundamental pellet properties other than strength; the fundamental material properties were not examined in this work.

\subsubsection{Effects of binders on Abrasion Index}

The effects of binder type and dose on the abrasion index of concentrates $\mathrm{D}$ and $\mathrm{F}$ are shown in Figure 12. Organic binder dose ranged from 0.5 to $2 \mathrm{~kg} / \mathrm{t}$ while bentonite dose ranged from 2 to $10 \mathrm{~kg} / \mathrm{t}$. Organic binders and bentonite clay were added at different doses in order to produce similar green-ball behavior during agglomeration and acceptable greenball properties. For both concentrates, using organic binders resulted in higher abrasion indices compared to bentonite-bonded pellets. Lowering the bentonite dose increased the Abrasion Index (AI) as reported by Meyer (1980), while there was no clear trend between dose and AI for the organic binders. 

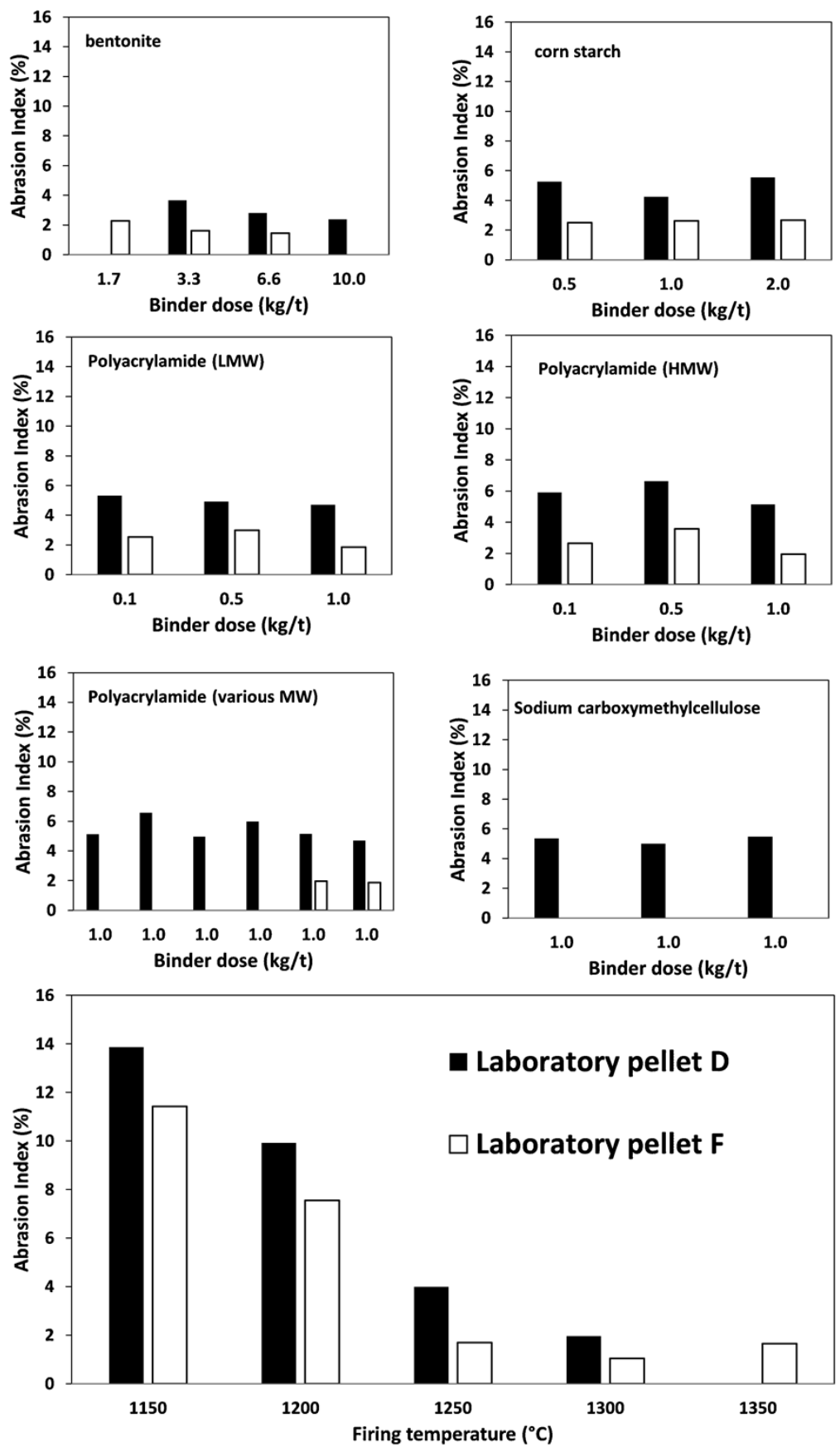

Figure 12 Effects of binders and firing temperature on the abrasion index of laboratory pellets. Unless otherwise indicated, all pellets were fired at $1250{ }^{\circ} \mathrm{C}$. Closed symbols are laboratory pellets made from concentrate $D$. Open symbols are laboratory pellets made from concentrate $F$. LMW = low molecular weight. $H M W=$ high molecular weight. $M W=$ molecular weight. The firing temperature samples were made using $6.6 \mathrm{~kg} / \mathrm{t}$ bentonite clay as the binder. 
At a single binder dose $(1 \mathrm{~kg} / \mathrm{t}$, concentrate $\mathrm{D})$, using different organic binders produced an AI that ranged from 4 to 6.5 pct. The wide range in AI may be due to the varying properties of the organic binders, and their effects on the final pellet microstructure. As an example, final green-ball moisture ranged from 8.5 to 10 pct. (wet basis) for those samples, which would tend to affect final pellet porosity. Increased pellet porosity, and the loss of additional inorganic material due to organic binders have been the major reported drawbacks to organic binder use (Eisele and Kawatra, 2003).

\subsubsection{Effects of firing temperature on Abrasion Index}

At a constant bentonite dose of $6.6 \mathrm{~kg} / \mathrm{t}$, pellet firing temperature significantly affected AI (Figure 12). Increasing firing temperature from 1150 to $1300{ }^{\circ} \mathrm{C}$ decreased AI from 12-14 to $1.0-2 \%$, with a slight increase in AI at $1350{ }^{\circ} \mathrm{C}$. A maximum was observed in the compression strength curve at $1300 \mu \mathrm{m}$, which has been explained by lower oxygen potential at higher temperatures.

Lower oxygen potentials would cause hematite to revert to magnetite, disrupting the pellet structure. Concentrate D was less abrasion resistant at all temperatures, perhaps due to its coarser grain size (Meyer 1980), but followed a similar trend as Concentrate F.

Figure 12 illustrates the sensitivity of AI in the region of typical firing temperatures. The AI for concentrates D and F decreased from 9.92 to $3.99 \%$, and 7.55 to $1.69 \%$ respectively, when firing temperature was raised from 1200 to $1250{ }^{\circ} \mathrm{C}$. Pellet firing temperature had the greatest effect on AI under the conditions tested here. However, bentonite effects may have been more pronounced if tested at lower firing temperatures.

\subsubsection{Size distributions of particulates generated by abrasion}

The effect of revolution time on powder fineness was determined by measuring the size distribution of powders after they were removed from the drum. The weight percent of material with aerodynamic diameters 10 micrometers and smaller is shown in Figure 13. Powder size distributions for each pellet type became finer with tumble time and appeared to stabilize at a specific percentile for each type of pellet.

Similar time-dependent behavior was observed with all pellet types, suggesting either a radial distribution of properties or structure within the pellet, or the attrition of coarse fragments from pellet surfaces during an initial pellet stabilization period. This second view would support previous results showing the importance of surface roughness on dust generation in the previously-used dust tower (Sivrikaya and Arol, 2013). The time dependent behavior also illustrated that relevant levels of degradation should occur during testing as dustiness rankings can change with time, unless low levels of handling and abrasion are expected - that is not the case for iron ore pellets. 


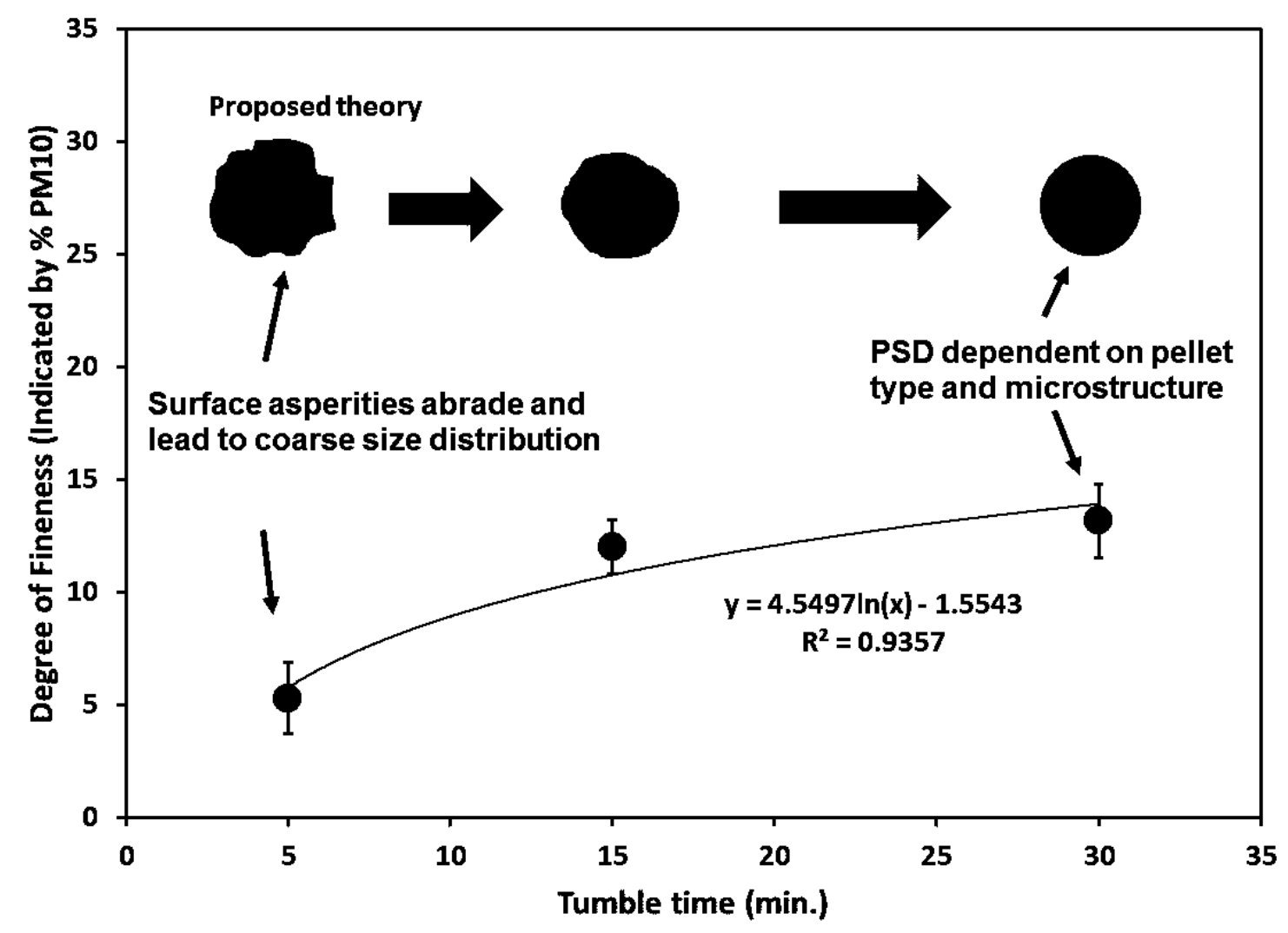

Figure 13 Effect of revolution time on abrasion powder fineness. Laboratory pellets made from Plant $D$ concentrate. Organic binders at $1.0 \mathrm{~kg} / \mathrm{t}$. Firing temperature $1250^{\circ} \mathrm{C}$.

Powder fineness (described by the 30 min. pct. $\mathrm{PM}_{10}$ ) did not tend to vary with organic binder dose, but varied with organic binder type, and increased with increasing pellet temperature and bentonite binder dose - all common agglomeration variables that affect Abrasion Indices. In general, the material-specific stabilization level is not understood, but thought to be influenced by pellet mineralogy and porosity, and their distribution within the pellet. Pellets that resisted degradation and abrasion the most tended to produce the finest powder size distributions.

This was observed in both concentrate types balled in the laboratory, and in the five industrial pellet samples. In effect, decreased pellet abrasion index appeared to lead to significantly greater proportions of material in size fractions generally considered as dust. Pellets with lower AI tended to produce powders with finer size distributions. The relationship between AI and powder fineness is shown in Figure 14. Good-quality pellets would have AI less than 5 percent. 


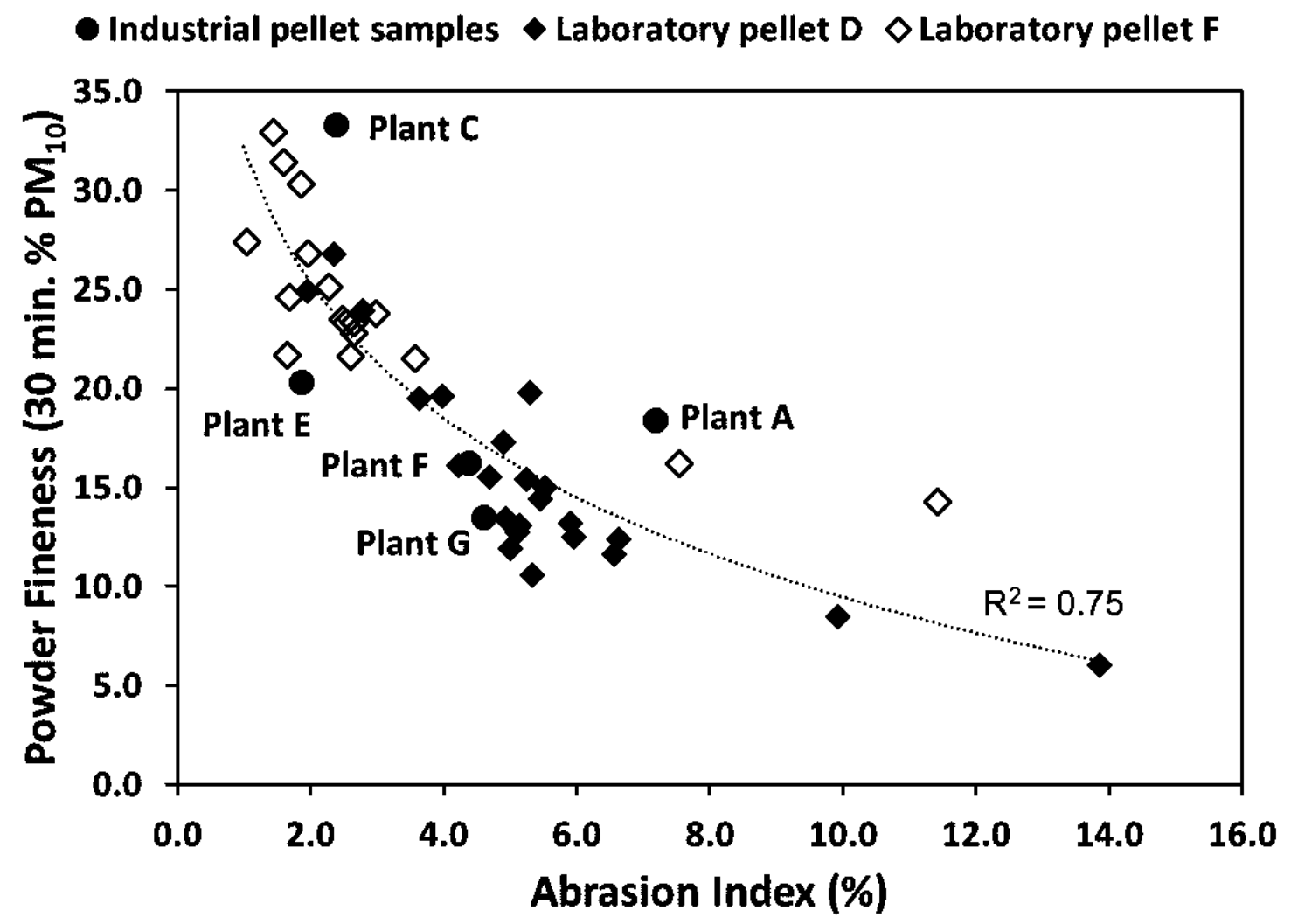

Figure 14 Effects of abrasion index on abrasion product fineness. As pellet quality improves (Al decreases), the degradation products generally become finer. The Abrasion Index was defined as the quantity of $-0.5 \mathrm{~mm}$ fines produced after 30 minutes, normalized to the initial pellet charge.

\subsubsection{Regression between pellet dustiness and the Abrasion Index}

The authors originally hypothesized that the abrasion index can be used as an empirical test of iron ore pellet dustiness. Consequently, the total quantity of $\mathrm{PM}_{10}$ was regressed to the Abrasion Index.

The total quantity of $\mathrm{PM}_{10}$ produced during abrasion was regressed to the Abrasion Index, as shown in Figure 15. Considering all 45 types of pellets, higher AI led to higher quantities of $\mathrm{PM}_{10}$ or potential material loss $\left(\mathrm{R}^{2}=0.58\right)$. Higher deviation existed at higher $\mathrm{AI}$, potentially arising from the different particle size distributions between the two iron concentrates. Concentrate $\mathrm{F}$ was finer $\left(\mathrm{P}_{80}=30 \mu \mathrm{m}\right)$, and logically had higher quantities of $\mathrm{PM}_{10}$. Concentrate $\mathrm{D}$ was coarser $\left(\mathrm{P}_{80}=49 \mu \mathrm{m}\right)$, and total $\mathrm{PM}_{10}$ stabilized at 0.8 pct. 
Industrial pellet samples $\square$ Laboratory pellet $D$ L Laboratory pellet F

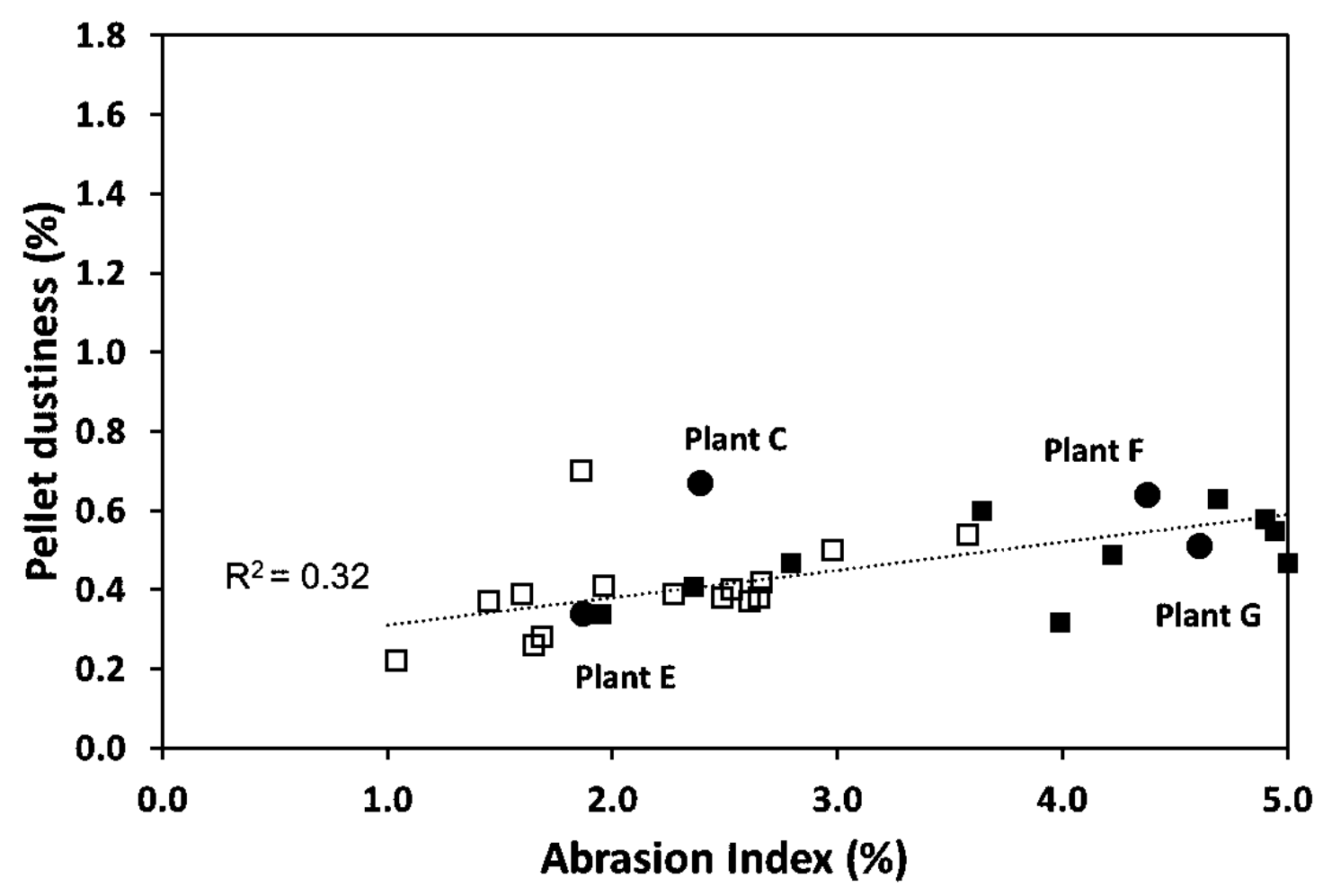

Figure 15 Effects of Abrasion Index on the total quantity of dust generated by abrasion. Only pellets with $A I<5 \%$ are shown. The Abrasion Index was defined as the quantity of $-0.5 \mathrm{~mm}$ fines produced after 30 minutes, normalized to the initial pellet charge. Dust was defined as the quantity of PM10 particles, normalized to the initial pellet charge.

The higher AI and dustiness levels were caused by under-firing pellets, as shown in Figure 12 and supported by the dust-tower conclusions in Chapter 2 of this thesis. Simply put, firing temperature was the greatest factor affecting the abrasion resistance and dustiness of iron ore pellets.

The correlation between total $\mathrm{PM}_{10}$ and $\mathrm{AI}$ was weak when only considering well-fired pellets with AI less than five percent (Figure 15). For well-fired pellets, the quantity of $\mathrm{PM}_{10}$ ranged from 0.2 to 0.7 percent. Laboratory pellets made from concentrates D and F, and the industrial pellet samples, generally appeared to lie on a single curve. The poor correlation may be explained by the effects of abrasion index on the size distributions of the abrasion powders. 


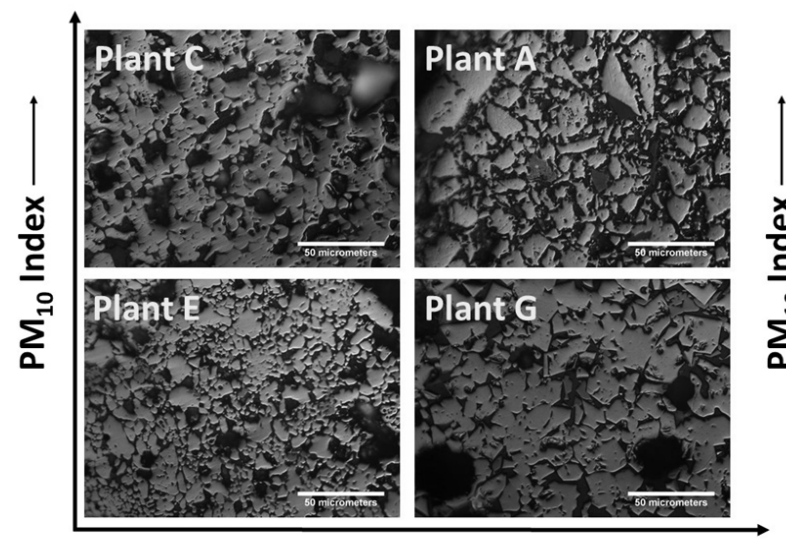

Abrasion Index

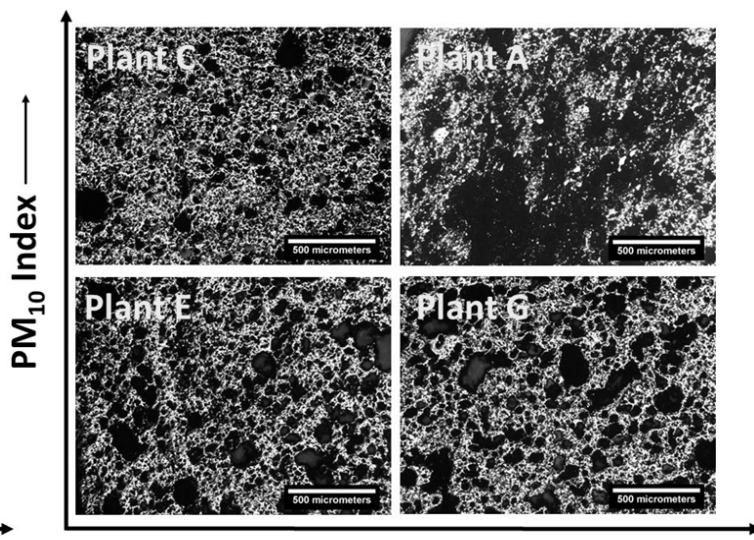

Abrasion Index

Figure 16 Cross-sectional micrographs of iron ore pellets at various Al and total $P M_{10}$. Micrographs were taken near the pellet surface. Microstructure and bonding of grains are shown at left (scale bar $50 \mu \mathrm{m}$ ), while overall pellet structure and porosity are shown at right (scale bar $500 \mu \mathrm{m}$ ).

In general, powder fineness significantly increased as the Abrasion Index decreased. AI decreased from five to one percent ( 80 percent decrease), while the powder fineness increased from 16.3 to 32.2 percnet over the same range (97 percent increase). As total quantities of $\mathrm{PM}_{10}$ generated by abrasion depend on the quantity of fines generated and the powder fineness, relatively small changes in total levels of $\mathrm{PM}_{10}$ were observed.

Figure 16 presents representative micrographs of pellet microstructures near the pellet surface. Five samples at AI ranging from two to seven percent were visualized. They are arranged by Abrasion Index (low-left to high-right) and total quantity of $\mathrm{PM}_{10}$ (low-bottom to high-top) in the figure.

Individual grains in Plant A pellets were very angular in nature with minimal growth between adjacent particles. Distinct layers or shells were observed in the pellets, and some regions of very high porosity were present. Plant $\mathrm{C}$ pellets, with a lower Abrasion Index, were compact, dense pellets with significant interconnectedness between adjacent grains. $\mathrm{E}$ and $\mathrm{G}$ type pellets had higher porosity porosity than A and $\mathrm{C}$ type pellets (see Table 2). From the limited samples visualized, it qualitatively appeared that the pellets with coarser, angular grains had higher abrasion indices, while the total $\mathrm{PM}_{10}$ increased with decreasing porosity.

Further work should be conducted on a wider range of pellet types including varying pellet basicity, increased number of ore types, and using a pot-grate firing procedure mimicking 
industrial pellet firing. A new abrasion unit is proposed which will continuously sample airborne particles during their generation.

\subsection{Conclusions}

Pellets fired in Straight Grate furnaces are less abrasion resistant than pellets fired in Grate Kiln furnaces, leading to higher levels of fines and dust.

The quantity of fines produced during abrasion and their size distribution are affected by pelletizing conditions, including ore type, binder type, binder dose, and firing temperature. These variables were varied within industrially relevant ranges, and their effects on fines generation and material loss were determined. Concluded from the study were:

- Firing temperature is the most important factor affecting pellet abrasion indices and dust generation.

- Abrasion resistant pellets tended to produce finer abrasion products than weakly bonded pellets. This observation may explain the poor correlation between AI and $\mathrm{PM}_{10}$ for well-fired iron ore pellets.

The results from Chapters 2 and 3 of this thesis suggest that material loss and levels of pellet dustiness may be significantly affected by pellet quality up to a certain point. Poorlyfired pellets will be dusty during handling and transportation, while well-fired pellets will generate less - but finer - material as their quality improves. This could lead to little observed changes in $\mathrm{PM}_{10}$ generation over a wide range of pellet quality. Dust generation at each site would then depend on the quantity of material and their extent of handling. 


\section{References}

1. ASTM C914-09. Standard Test Method for Bulk Density and Volume of Solid Refractories by Wax Immersion

2. ASTM E279 - 97(2010) "Standard Test Method for Determination of Abrasion Resistance of Iron Ore Pellets and Sinter by the Tumbler Test"

3. Bach, S., and Schmidt, E., (2008), "Determining the Dustiness of Powders-A comparison of three Measuring Devices" Annals of Occupational Hygiene Vol. 52, No. 8, pp. 717-728

4. Baron, P.A., and Willeke, K., (2001) "Ch. 3: Aerosol Fundamentals" in Aerosol Fundamentals: Principles, Techniques, and Applications (2 ${ }^{\text {nd }}$ Edition), P.A. Baron and K. Willeke, (Eds.), Wiley-Interscience

5. Copeland, C.R., and Kawatra, S.K., (2005), "Dust Suppression in Iron Ore Processing Plants" Minerals \& Metallurgical Processing 22.4: 177-191

6. Copeland, C.R., and Kawatra, S.K., (2011) "Design of a dust tower for suppression of airborne particulates for iron making", Minerals Engineering, Vol. 24, No. 13, pp. 1459-1466

7. EPA (2013), United States Environmental Protection Agency, Accessed on Internet: http://www.epa.gov/ncer/science/pm/

8. Fagerberg, B., and Sandberg, N., (1973) "Degradation of Lump Ores in Transport" Proceedings of the Second International Symposium on Transport and Handling of Materials, Volume 2, Rotterdam, Netherlands, October 1-5

9. Geerdes, M., Toxopeus, H., and van der Vliet, C., (2009), “Ch. 3: The Ore Burden: Sinter, Pellets, Lump ore" in Modern Blast Furnace Ironmaking: an introduction, $2^{\text {nd }}$ Edition, IOS Press

10. Gill, T.E., Zobeck, T.M., and Stout, J.E., (2006) “Technologies for laboratory generation of dust from geological materials" Journal of Hazardous Materials Vol. 132, pp. 1-13, doi:10.1016/j.jhazmat.2005.11.083

11. Godin, E., and Wilhelmy, J.F., (2008) "Development of a new layered pellet" Paper presented at the $2^{\text {nd }}$ COREM Symposium on Iron Ore Pelletization, 2-4 June, 2008

12. Gudenau, Prof., Kortman, Dr., and Papacek, Dr., (1985) "The influence of the diameter of iron ore pellets on their production parameters and on their metallurgical properties" Proceedings, $4^{\text {th }}$ International Symposium on Agglomeration, C.E. Capes (Ed.), Toronto, CA, pp. 329-334

13. Hanninen, M.J., Seppanen, T.E., Sundberg, C.R., and Suardini, P.J., (2003) "Internal carbon addition during hematite fluxed pellet production at the Tilden mine" SME Annual Meeting, Prepring 03-078, February 24-26, Cincinnati, Ohio

14. Hasenack, N.A., (1977) "Replacement of magnetite ores in the pellet feed mixture by hematite with coke breeze" Agglomeration 77, Volume 1, Chapter 24 (Abstract only), pp 436 
15. ISO 3271:2007 "Iron ores for blast furnace and direct reduction feedstocks -Determination of the tumble and abrasion indices"

16. ISO 4225:1994 Air quality -- General aspects - Vocabulary

17. IUPAC (1990) Glossary of atmospheric chemistry terms. International Union of Pure and Applied Chemistry, Applied Chemistry Division, Commission on Atmospheric Chemistry, Pure and Applied Chemistry 62(11):2167-2219

18. Jonsson, C.Y.C., Stjernberg, J., Wiinikka, H., Lindblom, B., Boström, D., and Öhman, M., (2013) "Deposit formation in a grate-kiln plant for iron-ore pellet production. Part 1: Characterization of process gas particles" Energy and Fuels, 27(6): 6159-6170

19. Kawatra, S.K. and Halt, J.A., (2010), "Binding effects in hematite and magnetite concentrates" International Journal of Mineral Processing Vol. 99, No. 1-4, pp. 39-42

20. Litster, J.D., Water, A.G., and Nicol, S.K., (1986) "A Quantitative Measure of Coke Abrasion" Transaction ISIJ, Vol. 26, 704-709

21. Martinovic, T.I., Ouellet, G., and Paquet, G., (1998) "Influence of Thermal Treatment and Handling Conditions on Fired Pellet Physical Properties", Ironmaking Conference Proceedings, 57:945-954

22. Meyer, K., (1980) "Pelletizing of Iron Ores" Springer-Verlag, Berlin,

23. Oja, K., (2013) "Straight Grate vs Grate Kiln", Paper presented at 2013 Duluth SME Conference

24. Pensis, I., Mareels, J., Dahmann, D., and Mark, D., (2010) “Comparative Evaluation of the dustiness of Industrial Minerals According to European Standard EN15051, 2006" Annals of Occupational Hygiene Vol. 54, No. 2, pp. 204-216, doi:10.1093/annhyg/mep077

25. Petavratzi, E., Kingman, S., and Lowndes, I., (2005) "Particulates from mining operations: A review of sources, effects and regulations" Minerals Engineering Vol. 18, pp. 1183-1199, doi:10.1016/j.mineng.2005.06.017

26. Pierce, T.J., Horton, A.E., and Tucker, J., (1980) "Coke breakage behavior in relation to its structure" J.Phys.D: Appl. Phys. 13, 953-967

27. Sivrikaya, O., and Arol, A.I., (2013) "An investigation of the relationship between compressive strength and dust generation potential of magnetite pellets" International Journal of Mineral Processing 123:158-164, http://dx.doi.org/10.1016/j.minpro.2013.06.006

28. Umadevi, T., Kumar, M.G.S., Babu, T.M., and Ranjan, M., (2008) "Optimization of carbon addition in pellet mix and its influence on pellet quality and microstructure" Paper presented at the $2{ }^{\text {nd }}$ COREM Symposium on Iron Ore Pelletization, 2-4 June 2008 